\title{
VARIÁVEIS AMBIENTAIS E A DISTRIBUIÇÃO DE ESPÉCIES ARBÓREAS EM UM REMANESCENTE DE FLORESTA ESTACIONAL SEMIDECÍDUA MONTANA NO CAMPUS DA UNIVERSIDADE FEDERAL DE LAVRAS, MG ${ }^{1}$
}

\author{
Fernando Del Bon Espírito-Santo ${ }^{1}$ \\ Ary Teixeira de Oliveira-Filho ${ }^{2}$ \\ Evandro Luiz Mendonça Machado ${ }^{3}$ \\ Josival Santos Souza ${ }^{3}$ \\ Marco Aurélio Leite Fontes ${ }^{3}$ \\ João José Granate de Sá e Melo Marques ${ }^{4}$
}

Recebido em 10/09/2001. Aceito em 27/02/2002.

\begin{abstract}
RESUMO - (Variáveis ambientais e a distribuição de espécies arbóreas em um remanescente de floresta estacional semidecídua montana no campus da Universidade Federal de Lavras, MG). Este trabalho teve como objetivo detectar padrões de distribuição espacial da comunidade arbórea de um fragmento de floresta estacional semidecídua montana e suas relações com variáveis ambientais, com ênfase nas variações catenárias do solo e efeito das bordas. O remanescente florestal, conhecido como Mata da Subestação, cobre uma área de 8,75 ha e está localizado no

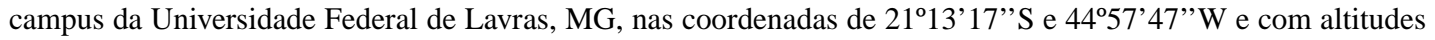
variando de 910 a $940 \mathrm{~m}$. A amostragem foi realizada por meio de duas transeções (A e B) separadas por $80 \mathrm{~m}$ e compostas, cada uma, por 21 e 31 parcelas contíguas de 20 x 20m de dimensões. As transeções foram lançadas no sentido da declividade maior da encosta e ligando bordas opostas do fragmento. Todos os indivíduos arbóreos com diâmetro à altura do peito (DAP) $\geq 5 \mathrm{~cm}$ presentes nas parcelas foram identificados e medidos (DAP e altura). Foi feito um levantamento topográfico detalhado da área amostrada. Amostras do solo superficial (0-20cm) foram coletadas em cada parcela para análise química e textural. O solo das parcelas foi classificado, sendo identificadas duas catenas que continham, da baixa para a alta encosta, Nitossolos e Latossolos (transeção A) e Nitossolos, Cambissolos e Latossolos (transeção B). O levantamento florístico geral, feito nas parcelas e no fragmento como um todo, registrou 238 espécies pertencentes a 143 gêneros e 57 famílias. Nas parcelas, os 3120 indivíduos amostrados pertenciam a 175 espécies, 115 gêneros e 49 famílias. O índice de diversidade de Shannon foi de $H=4,19$ nats.indivíduo ${ }^{-1}$, com equabilidade $S=0,81$, valores altos no contexto de levantamentos semelhantes na região. $\mathrm{O}$ elevado índice de espécie raras (densidade relativa $<1$ árvore.ha ${ }^{-1}$ ) de $34 \%$ sugere que o isolamento genético devido à fragmentação pode prejudicar a conservação biológica de muitas espécies a longo prazo. Os Latossolos de ambas
\end{abstract}

${ }^{1}$ Pós-graduação, Instituto Nacional de Pesquisas Espaciais, Av. dos Astronautas, 1758, 12201-027, São José dos Campos, SP, e-mail: fernando@ltid.inpe.br

${ }^{2}$ Departamento de Ciências Florestais, Universidade Federal de Lavras, 37200-000 Lavras, MG.

${ }^{3}$ Pós-graduação, Laboratório de Ciências Ambientais, CBB, Universidade Estadual do Norte Fluminense, Av. Alberto Lamego 2000, 28015-620 Campos dos Goytacazes, RJ.

${ }^{4}$ Departamento de Ciência do Solo, Universidade Federal de Lavras, 37200-000 Lavras, MG 
as transeções mostraram-se mais ácidos, pobres em bases trocáveis e ricos em alumínio que o Nitossolo e o Cambissolo. A composição e estrutura da comunidade arbórea diferiram entre os subgrupos de solo. Uma análise de correspondência canônica indicou correlações significativas entre variáveis topográficas e edáficas e a distribuição da abundância das espécies, mas nenhuma correlação clara com as bordas. As variáveis ambientais mais fortemente correlacionadas foram cota média, saturação por bases e teores de areia, silte e argila. Portanto, a distribuição das espécies arbóreas no fragmento parece ser primariamente influenciada pelo status nutricional e regime de água dos solos. A heterogeneidade edáfica e topográfica da área pode ter contribuído para tornar não detectável pelo método usado qualquer efeito da borda na composição e estrutura da comunidade.

Palavras-chave - Catenas, diversidade, fragmentação florestal, solos, topografia

ABSTRACT - (Environmental variables and the distribution of tree species within a remnant of tropical montane semideciduous forest in Lavras, southeastern Brazil). The purpose of the present contribution was to seek patterns of spatial distribution of the tree community in a remnant of tropical semideciduous forest and their correlation with environmental variables, stressing both catenary variations of soil properties and edge effects. The forest fragment, known as Mata da Subestação, covers an area of 8.75ha and is located on the campus of the Federal University of

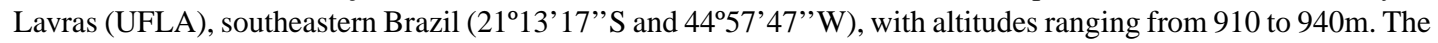
sampling was carried out using two transects, A and B, $80 \mathrm{~m}$ apart, containing 21 and 31 adjacent $20 \times 20 \mathrm{~m}$ quadrats, respectively. Both transects followed the direction of the main slope, linking opposite forest edges. In each quadrat all individuals with diameter at breast height $(\mathrm{dbh}) \geq 5 \mathrm{~cm}$ were identified to the species level and measured (dbh and height). A detailed topographical survey was carried out on the sampled area. Samples of the top $20 \mathrm{~cm}$ of soil were collected at the centre of each quadrat for chemical and textural analyses. The soils of each quadrat were classified and two soil catenas were identified: transect A contained Nitosols (lower slope) and Oxysols (upper slope) while transect B contained Nitosols (slope base), Cambisols (lower slope) and Oxysols (upper slope). The floristic survey performed in the sample transects and in the whole fragment totalled 238 species belonging to 143 genera and 57 families. The 3120 individuals recorded in the plots belonged to 175 species, 115 genera and 49 families. The Shannon diversity index $H=4,19$ nats.individual ${ }^{-1}$ and evenness $J=0,81$ were high when compared to similar surveys in the same region. The high index of rare species (relative density < $1 \%$ ) of $84,5 \%$ suggests that genetic isolation due to fragmentation may jeopardize the biological conservation of many species with time. The Oxysols of both transects were more acidic, poorer in exchangeable bases and richer in aluminium than Nitosols and Cambisols. The composition and structure of the tree community differed among the soil groups. Canonical correspondence analysis indicated that the abundance distribution of the species was significantly correlated with topographic and soil variables; there was no clear correlation with the forest edges. The most strongly correlated variables were the mean elevation, the saturation of bases and the proportions of sand, silt and clay. Therefore, the distribution of tree species in the fragment is apparently influenced primarily by soils nutritional status and ground water regime. The heterogeneity of both soils and topography may have contributed to make undetectable by the methods used any edge effect on the composition and structure of the tree community.

Key words - Catenas, diversity, forest fragmentation, soils, topography

\section{Introdução}

Os remanescentes de vegetação conhecidos como fragmentos florestais, advindos de vários anos de desmatamento progressivo, constituem hoje um dos maiores desafios para a conservação. Esses novos ambientes criados pelo homem abrigam uma diversidade biológica ainda não calculada e altamente ameaçada. $\mathrm{O}$ efeito da fragmentação pode ser avaliado no nível biótico e abiótico. No primeiro, o efeito se concreti- za em várias mudanças na estrutura e dinâmica da comunidade vegetal, na diversidade e abundância da fauna e nas interações entre ambas, como as causadas pela infestação de cipós, aumento de colonização por espécies alienígenas, interrupção do fluxo gênico e aumento da mortalidade de animais e plantas (Lovejoy \& Bierregaard 1990; Murcia 1995). Os efeitos abióticos não são menos importantes, mas são mais fáceis de serem percebidos e quantificados. Aumento da temperatura, radiação solar e evapo- 
transpiração, redução da umidade relativa e da retenção da precipitação, aumento do risco de erosão, assoreamento de cursos d'água e diminuição de resistência à ação do vento provocando queda de árvores são apenas alguns exemplos (Kapos 1989; Laurence \& Yensen 1991).

Esses efeitos bióticos e abióticos são mais pronunciados na borda do fragmento, onde existe um maior contato com o ambiente circundante, geralmente de forma abrupta, não existindo uma zona de tensão gradual na mudança da comunidade que opere como 'tampão'. O efeito borda é responsável por várias alterações na composição de espécies, estrutura e dinâmica das comunidades de plantas (Laurence et al. 1998).

No Brasil o processo da fragmentação florestal foi bem acentuado na Mata Atlântica. Ocupando $12 \%$ do território brasileiro, essa floresta está hoje reduzida a apenas $5 \%$, na forma de pequenos fragmentos de diferentes tamanhos, formas, graus de isolamento, tipos de vizinhança e históricos de perturbações, comprometendo a conservação de sua diversidade biológica (Viana 1990; Viana \& Tabanez 1996; SOS Mata Atlântica 1998). As florestas semidecíduas do domínio da Mata Atlântica, em particular, foram severamente reduzidas, uma vez que sua ocorrência coincide com os solos mais férteis e úmidos e, portanto, mais visados pela agropecuária (Oliveira-Filho et al. 1994a). Whitmore (1997) afirmou que a América do Sul abriga 46\% das florestas tropicais estacionais (semidecíduas e decíduas) do mundo, o que representa 272 milhões de hectares, sendo cerca de $0,96 \%$ desmatados anualmente. Estas taxas, estimadas para o período de 1981-1990, estão acima da média de $0,71 \%$ estimada para todas as florestas tropicais em conjunto, e bem acima da média estimada para as florestas ombrófilas, que é de 0,29\% (FAO 1993).

Desta forma, torna-se urgente a necessidade de se avaliar a diversidade biológica contida nos atuais fragmentos, por meio de sua quantificação, bem como compreender a organização espacial da comunidade nos fragmentos e a direção das mudanças nos processos ecológicos, o que permitirá avaliar os potenciais de perdas e conservação dos recursos naturais a longo prazo. A Região do Alto Rio Grande, no sul de Minas Gerais, é um dos focos atuais do Projeto de Conservação e Utilização Sustentável da Diversidade Biológica Brasileira (PROBIO), onde atua o subprojeto 'Estratégias para conservação e manejo da biodiversidade em fragmentos de florestas semidecíduas' executado pela EMBRAPA Recursos Genéticos, a Universidade Federal de Lavras (UFLA) e Universidade de Brasília (UnB). O presente trabalho integra este subprojeto e teve como objetivos centrais: (a) quantificar a diversidade de espécies arbóreas e (b) avaliar os principais fatores condicionantes da distribuição dessas espécies em um dos 21 fragmentos de floresta estacional semidecídua estudados na região, conhecido como Mata da Subestação e situado no campus da UFLA. Como ponto de partida, foram colocadas duas perguntas básicas: (a) como estão posicionadas a riqueza e diversidade de espécies arbóreas da Mata da Subestação em comparação com outros fragmentos da região? (b) o efeito borda é um dos principais fatores ambientais condicionantes da distribuição das espécies arbóreo-arbustiva no fragmento? (c) a heterogeneidade do terreno no interior do fragmento promovida pela variação dos solos e da topografia influencia na distribuição de espécies?

\section{Material e métodos}

Área de estudo - A Mata da Subestação situa-se no município de Lavras, sul de Minas Gerais, nas coordenadas geográficas $21^{\circ} 13^{\prime} 17^{\prime}$ 'S e $44^{\circ} 57^{\prime} 47^{\prime} \mathrm{W}$, integrando uma área de propriedade do Ministério da Agricultura que foi cedida, em regime de comodato, à Universidade Federal de Lavras. $\mathrm{O}$ fragmento florestal cobre uma área de 8,75ha e reveste a encosta de um morro, apresentando pedoforma do tipo conve- 
xo-convexa e altitudes variando entre 910 e 940m (Fig. 1). Apesar dessa pedoforma ser característica de Latossolos (Resende et al. 1995), estes são encontrados da meia encosta para o topo, sendo substituídos por Nitossolos ou Cambissolos na base da encosta, onde existe a influência de intrusões de gabro, uma rocha magmática plutônica. O clima da região é do tipo $\mathrm{Cwb}$ de Köppen (mesotérmico com verões brandos e suaves e estiagens de invernos); a precipitação e a temperatura médias anuais são de 1493,2 mm e $19,3^{\circ} \mathrm{C}$, respectivamente, com $66 \%$ da precipitação ocorrendo no período de novembro a fevereiro (Vilela \& Ramalho 1979).

A vegetação da Mata da Subestação classifica-se como Floresta Estacional Semidecídua Montana e insere-se no domínio da Mata Atlântica sensu lato (Oliveira-Filho \& Fontes 2000).

$\mathrm{O}$ fragmento está isolado de outros fragmentos mais próximos a distâncias nunca inferiores a $1 \mathrm{~km}$. Atualmente está circundado, por uma matriz de baixa biomassa. Confronta-se com uma lavoura de café ao norte, noroeste e nordeste, uma plantação de banana ao sudoeste e pastagem no restante. Moradores antigos da Subestação informaram que na década de 1950 o fragmento sofreu um corte raso motivado pela iminência de desapropriação. Eles relataram também que, desde então, a floresta regenerou sem interrupções, havendo apenas a retirada ocasional e em baixa escala de lenha seca e madeira (' um pau ou outro pra cabo de enxada ou esco$r a ')$.

Na opinião deles, a regeneração foi rápida porque muitas árvores rebrotaram das cepas. Grandes exemplares de Cariniana legalis e Balfourodendron riedelianum parecem confirmar os relatos. No ano 2000, no entanto, cerca de 0,25 ha da área da Mata da Subestação foram removidos pela construção de uma estrada.

Levantamento da comunidade arbórea - A comunidade arbórea da Mata da Subestação foi amostrada por meio de duas transeções de $40 \mathrm{~m}$ de largura, paralelas e distantes de $80 \mathrm{~m}$ entre si, e que foram dispostas de forma a representar a maior variação aparente do gradiente fisionômico da vegetação, ou seja, cruzando o fragmento no sentido da maior declividade da encosta e ligando bordas opostas (Fig. 1). Esta disposição procurou ainda detectar possíveis efeitos de catenas de solo e das bordas do fragmento, seguindo as diretrizes de Oliveira-Filho (1994) e Viana (1992). As transeções A e B foram subdivididas, respectivamente, em 21 e 31 parcelas contíguas de $20 \times 20 \mathrm{~m}$. A área amostral total, de 2,08ha, representou $24 \%$ da área do fragmento, o que é uma proporção alta, comparando-se a outros levantamentos semelhantes feitos na região (Oliveira-Filho et al. 1994c).

Foram registradas informações para todos os indivíduos arbóreos vivos e com DAP (diâmetro à altura do peito) $\geq 5 \mathrm{~cm}$ presentes nas parcelas. As informações foram: a identidade da espécie; o DAP, medido com fita métrica; e a altura, estimada com auxílio de vara graduada.

Os indivíduos foram identificados no campo apenas no caso de espécies muito bem conhecidas; os demais tiveram amostras de material botânico coletadas para posterior identificação. Também foram feitas coletas de material botânico adicional fora das parcelas durante caminhadas de varredura em toda a Mata da Subestação, com o propósito de fazer um levantamento florístico mais completo de sua flora arbórea. Esse material foi herborizado e depositado no Herbário da Universidade Federal de Lavras (ESAL). As identificações foram feitas nos Herbários ESAL, do Jardim Botânico do Rio de Janeiro (RB) e do Instituto de Botânica de São Paulo (SP) por meio de comparações com amostras existentes e com auxílio de especialistas vinculados aos mesmos. As espécies foram classificadas nas famílias reconhecidas pelo APG, Angiosperm Phylogeny Group (1998).

Obtenção das variáveis ambientais - Foi realizado um levantamento topográfico da Mata da 
Subestação, sendo este mais detalhado no setor onde foram dispostas as transeções amostrais. A inclinação do terreno foi medida com auxílio de um hipsômetro de Suunto, sendo calculadas as distâncias verticais entre os pontos referenciais. De posse das cotas destes pontos, foram traçadas, em um mapa do fragmento, curvas de nível equiidistantes de $2 \mathrm{~m}$. Em seguida, foram extraídas coordenadas altimétricas do mapa utilizadas para produzir uma representação tridimensional da área (Fig. 1C) com auxílio do programa SURFER Versão 5.0, da Golden Software. As coordenadas dos vértices das parcelas permitiram também obter duas variáveis topográficas por parcela: cota média, obtida a partir da média das quatro cotas dos vértices, e desnível, obtido pela diferença entre as cotas máxima e mínima.

A extensão para o interior de um fragmento até onde é possível detectar os efeitos da borda é ainda bastante polêmica e uma dificuldade tem sido a produção de uma medida geométrica eficiente para avaliar o efeito borda (Murcia 1995). A influência de uma borda sobre qualquer ponto no interior da floresta não deve ser avaliada a partir de uma simples medida de distância até a borda mais próxima porque esta desconsidera o contorno da borda e a influência de vários pontos ao longo deste contorno (Malcolm 1994).

Portanto, para avaliar o efeito borda na distribuição das espécies foi produzido um 'fator de borda' para cada parcela, de acordo com o método utilizado por Oliveira-Filho et al. (1997) na Reserva Florestal da UFLA. Este consiste do comprimento linear do contorno da borda medido entre dois (ou mais) pontos de intercessão com um círculo cujo raio tem origem no centro da parcela. O comprimento deste raio representaria o raio de ação máxima do efeito borda sobre a comunidade arbórea, tendo sido fixado em $70 \mathrm{~m}$ pelos autores acima. No entanto, neste estudo o raio foi ampliado para $100 \mathrm{~m}$ porque, segundo Laurence et al. (1998), esta distância definiria a faixa onde as bordas influenciam mais fortemente na distribuição das plantas dentro de fragmentos florestais da Amazônia Central.

Os solos de cada parcela foram classificados segundo o novo Sistema Brasileiro de Classificação de Solo (EMBRAPA 1999) até o nível de subgrupo ( $4^{\circ}$ nível categórico), bem como nos grupamentos texturais e classes de drenagem. Foram coletadas amostras compostas do solo superficial $(0-20 \mathrm{~cm})$ de cada parcela. Cada amostra composta, com cerca de $500 \mathrm{~g}$ de solo, foi obtida pela mistura e homogeneização de cinco subamostras coletadas aleatoriamente na parcela. As amostras foram enviadas para o Laboratório de Solos do Departamento de Ciência do Solo da UFLA para análises químicas e texturais, realizadas segundo o protocolo da EMBRAPA (1997). As variáveis de solo obtidas foram: $\mathrm{pH}$; teores de $\mathrm{P}, \mathrm{K}, \mathrm{Ca}, \mathrm{Mg}$ e $\mathrm{Al}$; soma de bases (valor $\mathrm{S}$ ) e saturação por bases (valor V); matéria orgânica e teores de areia, silte e argila. As variáveis de solo foram comparadas entre os quatro subgrupos de solos encontrados nas transeções por meio de estatística descritiva.

Estrutura da comunidade arbórea - Foram calculados para as espécies presentes na amostra os seguintes parâmetros quantitativos: alturas média e máxima das árvores; densidades absoluta (árvores por hectare) e relativa (\% das árvores); dominâncias absoluta (área basal por hectare) e relativa (\% da área basal total); e valor de cobertura (densidade relativa + dominância relativa). Os valores de densidade, área basal e volume cilíndrico (área basal x altura) por hectare também foram calculados para cada parcela. Estes cálculos foram executados através do programa FITOPAC 2 (Shepherd 1994). A densidade, a área basal e o volume por hectare foram comparados entre os quatro subgrupos de solos encontrados nas transeções por meio de estatística descritiva. Foram preparadas distribuições de densidade de árvores por classes de diâmetro e altura para cada subgrupo de solo 
empregando intervalos de classe com amplitudes crescentes para compensar o forte decréscimo da densidade nas classes de tamanho maiores (Oliveira-Filho et al. 2001).

Para a determinação da diversidade de espécies foram calculados os índices de diversidade de Shannon $(H)$ e de equabilidade de Pielou $(J)$ (Brower \& Zar 1984) para a amostra total e subamostras correspondentes aos subgrupos de solos. Os valores de $H$ obtidos para os subgrupos de solos foram comparados aos pares pelo teste de $t$ de Hutcheson (Zar 1996). Para se evitar o problema de intensidades amostrais diferentes em comparações entre índices, foram selecionadas $N=9$ parcelas por subgrupo de solo. Correlações entre espécies e variáveis ambientais - Foi realizada uma análise de correspondência canônica, CCA (ter Braak 1987; 1995), para investigar a correlações entre a distribuição das abundâncias das espécies na amostra e as variáveis ambientais e utilizando-se o programa PC-ORD for Windows versão 4.14 (McCune \& Mefford 1999). A matriz de abundância das espécies consistiu do número de indivíduos por parcela, incluindo apenas as 64 espécies amostradas com mais de 10 indivíduos. Como recomendado por ter Braak (1995), os valores de abundância sofreram transformação logarítmica antes de se processar a análise porque as distribuições mostravam freqüências muito baixas para os valores mais elevados. A matriz de variáveis ambientais por parcela incluía inicialmente as 12 variáveis de solo, as duas variáveis topográficas (cota média e desnível) e 'fator borda'. Após uma análise preliminar, oito destas variáveis foram eliminadas devido à alta redundância (fator de inflação da variância > 20) ou correlações fracas $(<0,4$ com eixos 1 e 2$)$. No primeiro caso, estavam as variáveis $\mathrm{K}, \mathrm{Ca}$, $\mathrm{Mg}$ e valor $\mathrm{S}$, muito redundantes e melhor representadas pelo valor $\mathrm{V}$. O segundo caso incluiu as variáveis 'fator borda', desnível, $\mathrm{P}$ e matéria orgânica. Uma CCA processada com somente o 'fator borda' também não produziu correlações significativas. As sete variáveis remanescentes foram cota média, $\mathrm{pH}, \mathrm{Al}$, valor $\mathrm{V}$, areia, silte e argila. O teste de permutação de Monte Carlo (ter Braak 1988) foi aplicado para verificar a significância das correlações globais sumarizadas nos dois primeiros eixos de ordenação.

\section{Resultados e discussão}

Solos - Foram encontrados quatro subgrupos de solos dispostos em duas catenas correspondentes às duas transeções amostrais (Fig. 1B). A catena (transeção) A continha, na baixa encosta, Nitossolos Vermelhos Eutroférricos típicos, moderadamente drenados e com textura média a argilosa (parcelas A1 a A12) e, na alta encosta, Latossolos Vermelho-Amarelos Distroférricos argissólicos, bem drenados e com textura argilosa (parcelas A13 a A21). A catena B continha os mesmos Nitossolos na base da encosta (parcelas B1 e B2), seguidos de CAmBISsolos HÁPlicos Tb Distróficos argissólicos, bem drenados e com textura média (baixa encosta, parcelas B3 a B12) e Latossolos Vermelho-AmaRELOS Distroférricos típicos, acentuadamente drenados e com textura argilosa (alta encosta, parcelas B13 a B31). Para simplificar, os quatro subgrupos de solo serão denominados, a partir daqui, de Nitossolo, Cambissolo e Latossolos A e B.

Na Tabela 1, podem ser observadas as principais diferenças nas propriedades químicas e texturais entre os subgrupos de solos. O Nitossolo apresentou os maiores teores de $\mathrm{K}$, $\mathrm{Ca}$ e $\mathrm{Mg}$ e menores de $\mathrm{Al}$, resultando em valores mais elevados de soma de bases (S) e saturação por bases (V) entre todos solos, além de mostrar o $\mathrm{pH}$ mais elevado e o maior teor de matéria orgânica. O Cambissolo destaca-se pelo elevado teor de $\mathrm{K}$ e maior percentagem de areia e menor de argila. O Latossolo B mostrou-se mais ácido e pobre em bases que o Latossolo A. Em síntese, se os valores $\mathrm{S}$ e $\mathrm{V}$ forem adotados como medida de status nutricional dos solos, haveria o se- 
(A)

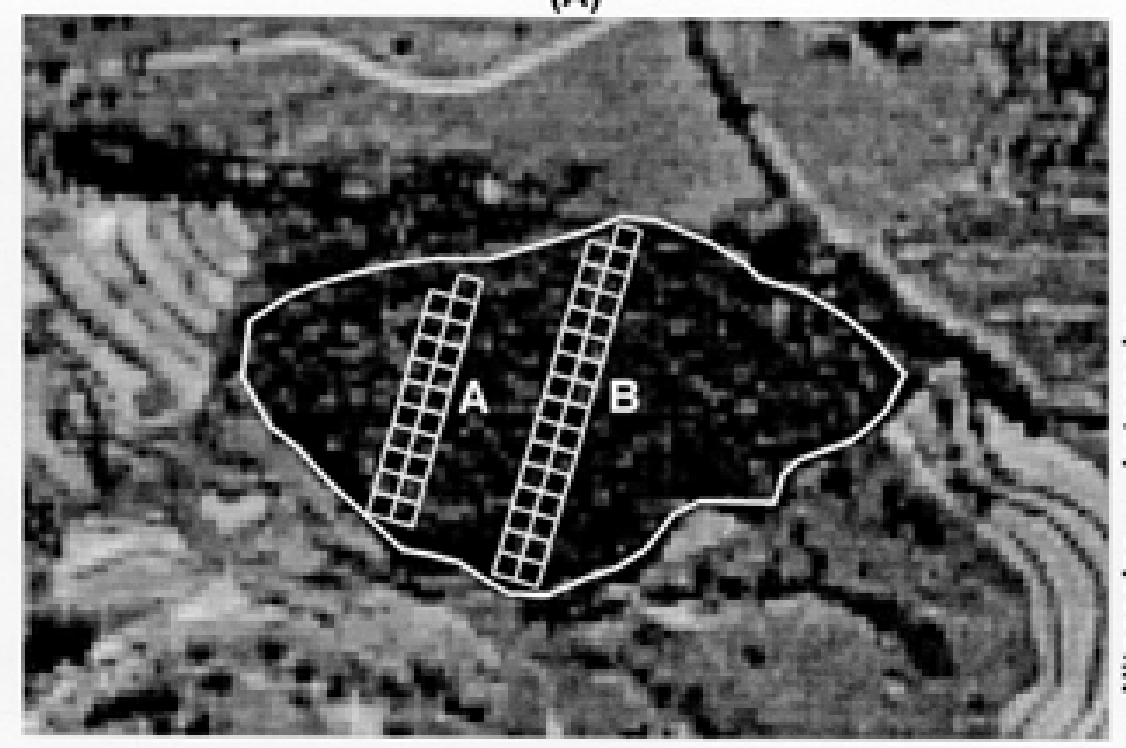

(C)

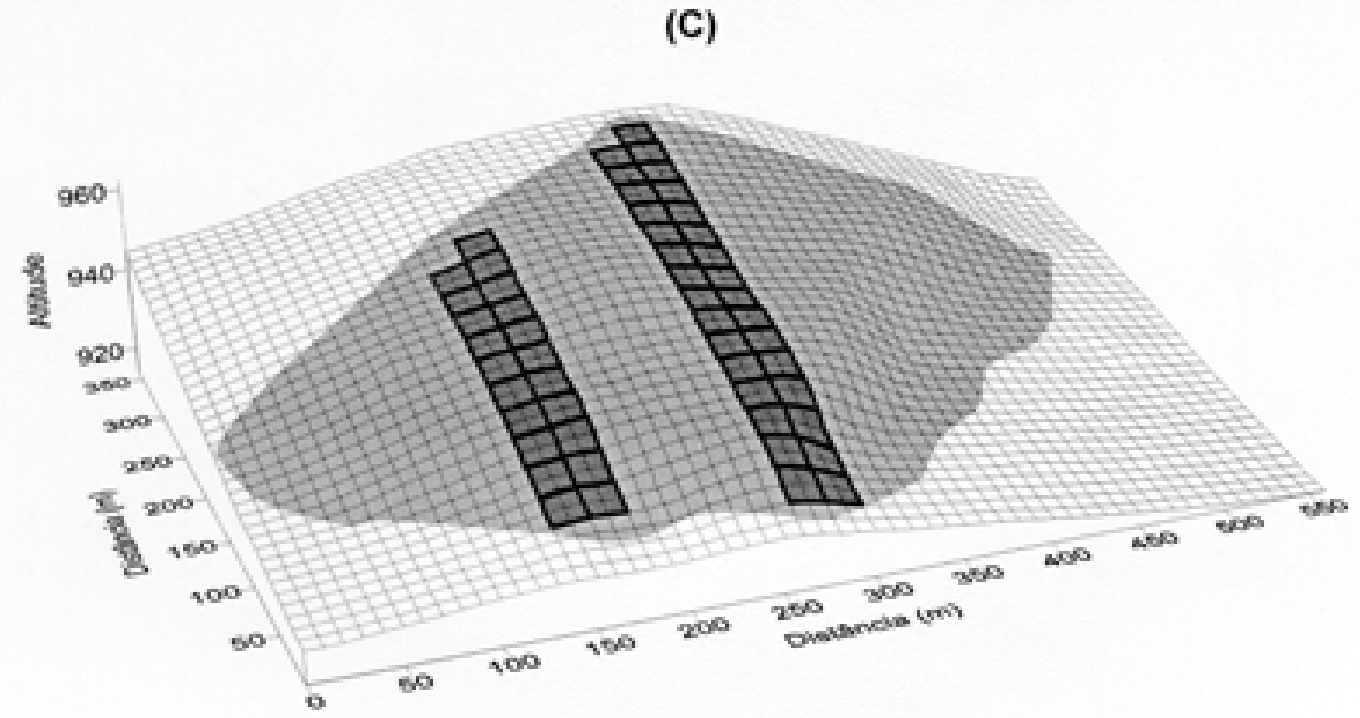

Figura 1. Mata da Subestação, Lavras, MG: (A) fotografia aérea mostrando a disposição das duas transeções amostrais (A e B) no interior do fragmento florestal; (B) identificação das parcelas e classificação dos solos; (C) diagrama de superfície mostrando o relevo do fragmento.

guinte gradiente de fertilidade crescente: Nitossolo $\rightarrow$ Cambissolo/Latossolo $\mathrm{A} \rightarrow$ Latossolo B. Este mesmo gradiente coincide com classes de drenagem crescentemente mais fortes.

As diferenças encontradas entre o Nitossolo e os demais solos podem ser consideradas
(B)

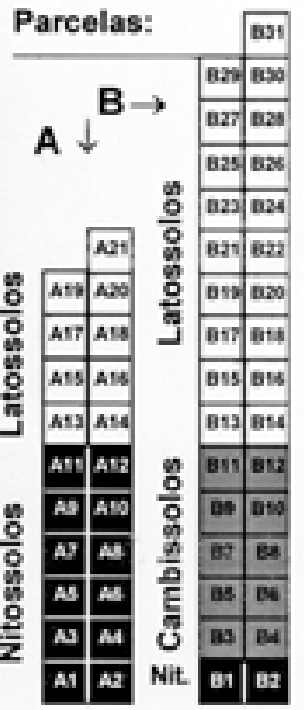

como dentro do esperado para solos cujo material de origem é constituído de rochas máficas, os quais, de maneira geral, tendem a ser mais ricos em bases trocáveis que aqueles derivados de rochas pelíticas (Curi et al. 1993, Resende et al. 1995). A influência pedogenética de uma in- 
Tabela 1. Variáveis químicas e granulométricas de 52 amostras do solo superficial $(0-20 \mathrm{~cm})$ coletadas na Mata da Subestação, Lavras, MG. Os valores são médias \pm desvios padrão das $\mathrm{N}$ amostras de cada um dos quatro subgrupos de solo.

\begin{tabular}{|c|c|c|c|c|c|}
\hline $\begin{array}{l}\text { Subgrupos } \\
\text { de solos }\end{array}$ & $\mathrm{N}$ & $\begin{array}{c}\mathrm{pH} \\
\mathrm{em} \mathrm{H}_{2} \mathrm{O}\end{array}$ & $\begin{array}{l}\text { P - Mehlich } \\
\left(\mathrm{mg} \mathrm{dm}^{-3}\right)\end{array}$ & $\begin{array}{c}\mathrm{K}^{+} \\
\left(\mathrm{mg} \cdot \mathrm{dm}^{-3}\right)\end{array}$ & $\begin{array}{c}\mathrm{Ca}^{++} \\
\left(\mathrm{cmolc} \cdot \mathrm{dm}^{-3}\right)\end{array}$ \\
\hline Nitossolo & 14 & $5,3 \pm 0,3$ & $1,0 \pm 0,0$ & $92 \pm 23$ & $2,9 \pm 1,3$ \\
\hline Latossolo A & 9 & $4,6 \pm 0,3$ & $1,0 \pm 0,0$ & $39 \pm 12$ & $1,3 \pm 0,5$ \\
\hline Cambissolo & 10 & $4,4 \pm 0,2$ & $1,6 \pm 0,5$ & $73 \pm 22$ & $0,9 \pm 0,3$ \\
\hline \multirow[t]{2}{*}{ Latossolo B } & 19 & $4,2 \pm 0,3$ & $1,0 \pm 0,0$ & $31 \pm 6$ & $0,5 \pm 0,2$ \\
\hline & & $\begin{array}{c}\mathrm{Mg}^{++} \\
\left(\mathrm{cmolc}^{+\mathrm{dm}^{-3}}\right)\end{array}$ & $\begin{array}{c}\mathrm{Al}^{+++} \\
\left(\mathrm{cmolc}^{+1 \mathrm{dm}^{-3}}\right)\end{array}$ & $\begin{array}{c}\text { Soma de bases } \\
\left(\mathrm{cmolc}^{\left.-\mathrm{dm}^{-3}\right)}\right.\end{array}$ & $\begin{array}{c}\text { Saturação por } \\
\text { bases }(\%)\end{array}$ \\
\hline Nitossolo & 14 & $1,7 \pm 0,4$ & $0,1 \pm 0,1$ & $4,9 \pm 1,6$ & $58 \pm 11$ \\
\hline Latossolo A & 9 & $0,8 \pm 0,5$ & $1,0 \pm 0,8$ & $2,2 \pm 0,9$ & $29 \pm 11$ \\
\hline Cambissolo & 10 & $0,8 \pm 0,4$ & $1,0 \pm 0,2$ & $1,8 \pm 0,6$ & $26 \pm 9$ \\
\hline \multirow[t]{2}{*}{ Latossolo B } & 19 & $0,2 \pm 0,1$ & $1,4 \pm 0,2$ & $0,8 \pm 0,3$ & $10 \pm 4$ \\
\hline & & $\begin{array}{l}\text { Mat. Orgânica } \\
(\%)\end{array}$ & $\begin{array}{c}\text { Areia } \\
(\%)\end{array}$ & $\begin{array}{l}\text { Silte } \\
(\%)\end{array}$ & $\begin{array}{l}\text { Argila } \\
(\%)\end{array}$ \\
\hline Nitossolo & 14 & $3,1 \pm 0,9$ & $44 \pm 7$ & $22 \pm 4$ & $34 \pm 4$ \\
\hline Latossolo A & 9 & $2,5 \pm 0,5$ & $46 \pm 5$ & $16 \pm 3$ & $38 \pm 2$ \\
\hline Cambissolo & 10 & $2,3 \pm 0,3$ & $63 \pm 4$ & $15 \pm 3$ & $22 \pm 5$ \\
\hline Latossolo B & 19 & $2,3 \pm 0,5$ & $48 \pm 9$ & $10 \pm 3$ & $43 \pm 11$ \\
\hline
\end{tabular}

trusão de gabro ocasionou a formação de uma mancha de Nitossolos no fundo do vale da Subestação, a qual é excepcional na região de Lavras (N. Curi, comunicação pessoal). À medida que se eleva a posição topográfica na catena local, diminui a influência do gabro nas características dos solos e aumenta a idade pedogenética, ambos acarretando a redução do status nutricional dos solos. A ocorrência de Cambissolo apenas na catena B provavelmente deve-se à topografia porque essa área é mais inclinada e sujeita a uma erosão laminar mais pronunciada, o que pode ter favorecido o rejuvenescimento dos solos da baixa encosta. A textura mais grossa reforça esta hipótese, indicando que partículas maiores podem ter resistido mais ao transporte pela erosão.

Estrutura fisionômica da comunidade arbórea A densidade de árvores não variou expressivamente entre os quatro subgrupos de solo da amostra, mas a área basal por hectare foi clara- mente mais elevada no Cambissolo e mais baixa no Latossolo B (Tab. 2). O volume por hectare também foi mais elevado no Cambissolo, mas a média mais baixa verificou-se no Nitossolo. Como o Cambissolo situa-se em uma posição intermediária no gradiente nutricional e de drenagem, fica difícil associar sua maior biomassa 'em pé' a extremos de fertilidade ou regime de água dos solos. Contudo, pode-se presumir que seu relevo mais acentuado e solos de textura mais grossa, associados à situação topográfica e ao caráter argissólico do horizonte B otimizem o balanço entre drenagem e armazenamento de água (Buckman \& Brady 1969, Resende et al. 1988), propiciando uma maior produtividade primária líquida do ecossistema. $\mathrm{O}$ volume mais baixo encontrado no Nitossolo, que é o mais rico em nutrientes, porém com drenagem mais restrita, também sugere que o regime de água do solo pode estar exercendo uma forte influência restritiva. No Latossolo $\mathrm{B}$, a maior pobreza nutricional associada à 
Tabela 2. Características estruturais e de composição da comunidade arbórea amostrada nas parcelas correspondentes aos quatro subgrupos de solo e na amostra total da Mata da Subestação, Lavras, MG. Para densidade, área basal e volume de árvores por hectare, os valores são médias \pm desvios padrão nas $N$ parcelas. Para número de espécies/indivíduos, índice de diversidade de Shannon $\left(H^{\prime}\right)$ e equabilidade de Pielou $\left(J^{\prime}\right)$, foram utilizadas subamostras de 9 parcelas por subgrupo de solo.

\begin{tabular}{lcccc}
\hline Subgrupos de solos & $N$ & $\begin{array}{c}\text { Densidade } \\
\left(\text { árvores.ha }{ }^{-1}\right)\end{array}$ & $\begin{array}{c}\text { Área basal } \\
\left(\mathrm{m}^{2} \cdot \mathrm{ha}^{-1}\right)\end{array}$ & $\begin{array}{c}\text { Volume } \\
\left(\mathrm{m}^{3} \cdot \mathrm{ha}^{-1}\right)\end{array}$ \\
\hline Nitossolo & 12 & $1434 \pm 203$ & $26,87 \pm 6,20$ & $320,6 \pm 119,5$ \\
Latossolo A & 9 & $1411 \pm 224$ & $28,59 \pm 7,71$ & $427,5 \pm 158,2$ \\
Cambissolo & 12 & $1700 \pm 229$ & $32,45 \pm 7,12$ & $566,0 \pm 196,1$ \\
Latossolo B & 19 & $1486 \pm 271$ & $24,13 \pm 5,99$ & $379,0 \pm 127,2$ \\
Amostra total & 52 & $1500 \pm 253$ & $27,24 \pm 7,07$ & $407,6 \pm 165,6$ \\
\hline & & $\mathrm{N}^{\circ}$ espécies/ & $H^{\prime}$ & $J$ \\
& 9 & $\mathrm{~N}^{\circ}$ indivíduos & (nats.individuo $\left.{ }^{-1}\right)$ & \\
\hline Nitossolo & 9 & $99 / 531$ & 3,80 & 0,83 \\
Latossolo A & 9 & $98 / 508$ & 4,04 & 0,88 \\
Cambissolo & 9 & $89 / 596$ & 3,56 & 0,79 \\
Latossolo B & 9 & $174 / 3120$ & 3,88 & 0,87 \\
Amostra total & 52 & 4,19 & 0,81 \\
\hline
\end{tabular}

drenagem mais pronunciada provavelmente limitam mais fortemente a produtividade primária líquida.

A distribuição de diâmetros foi muito semelhante em todos os subgrupos de solos (Fig. 2), mas houve diferenças marcantes na distribuição de alturas, com a densidade de árvores baixas (altura $<5 \mathrm{~m}$ ) caindo no sentido Nitossolo $\rightarrow$ Latossolo A $\rightarrow$ Cambissolo $\rightarrow$ Latossolo B, um padrão muito semelhante ao do gradiente de fertilidade crescente e drenagem mais forte. Esta tendência sugere um sub-bosque mais denso nos sítios com maior disponibilidade de água e mais ricos em nutrientes, o que poderia ser mais favorável à sobrevivência e crescimento de árvores sob baixa luminosidade. A tendência oposta é observada para as classes de altura mais elevadas (>10m), onde a densidade de árvores aumenta no sentido de fertilidade decrescente e drenagem mais forte. Nesses sítios de solos mais pobres e secos, o sub-bosque menos denso provavelmente propicia uma competição mais relaxada entre as árvores, favorecendo seu crescimento até o dossel. Além disso, as árvores do dossel são mais delgadas e de copas menos amplas, preenchendo espaços menores que nos sítios de solos mais ricos e úmidos.

Comparando-se com levantamentos feitos na região empregando o mesmo critério de inclusão (DAP $\geq 5 \mathrm{~cm}$ ), a área basal da Mata da Subestação $\left(27,24 \mathrm{~m}^{2} \mathrm{ha}^{-1}\right)$ foi bem superior à da Reserva Florestal da UFLA (Oliveira-Filho et al. 1994a), de $19,77 \mathrm{~m}^{2} \mathrm{ha}^{-1}$, mas semelhante à dos fragmentos da Mata do Capivari, em Lavras (Souza 2001), de 27,70m²ha ${ }^{-1}$, Mata da Ilha, em Ingaí, (Botrel 2001), de 29,31 $\mathrm{m}^{2} \mathrm{ha}^{-1}$, e Mata do Galego, em Luminárias (Rodrigues 2001), de 28,33 $\mathrm{m}^{2} \mathrm{ha}^{-1}$. A densidade da Mata da Subestação, de 1500 árvores.ha-1, é também superior à da Reserva da UFLA, de 1295 árvores.ha ${ }^{-1}$, apesar de os dois fragmentos ficarem a pouco mais de $1 \mathrm{~km}$ de distância. Os valores mais baixos da Reserva da UFLA podem estar ligados à menor fertilidade dos solos, baixa disponibilidade de água e perturbações mais intensas sofridas no passado (Oliveira-Filho et al. 1994a; 1997). As outras florestas tiveram densidade semelhante, como a Mata do Capivari, com 1488 árvores.ha ${ }^{-1}$, ou 
(A)

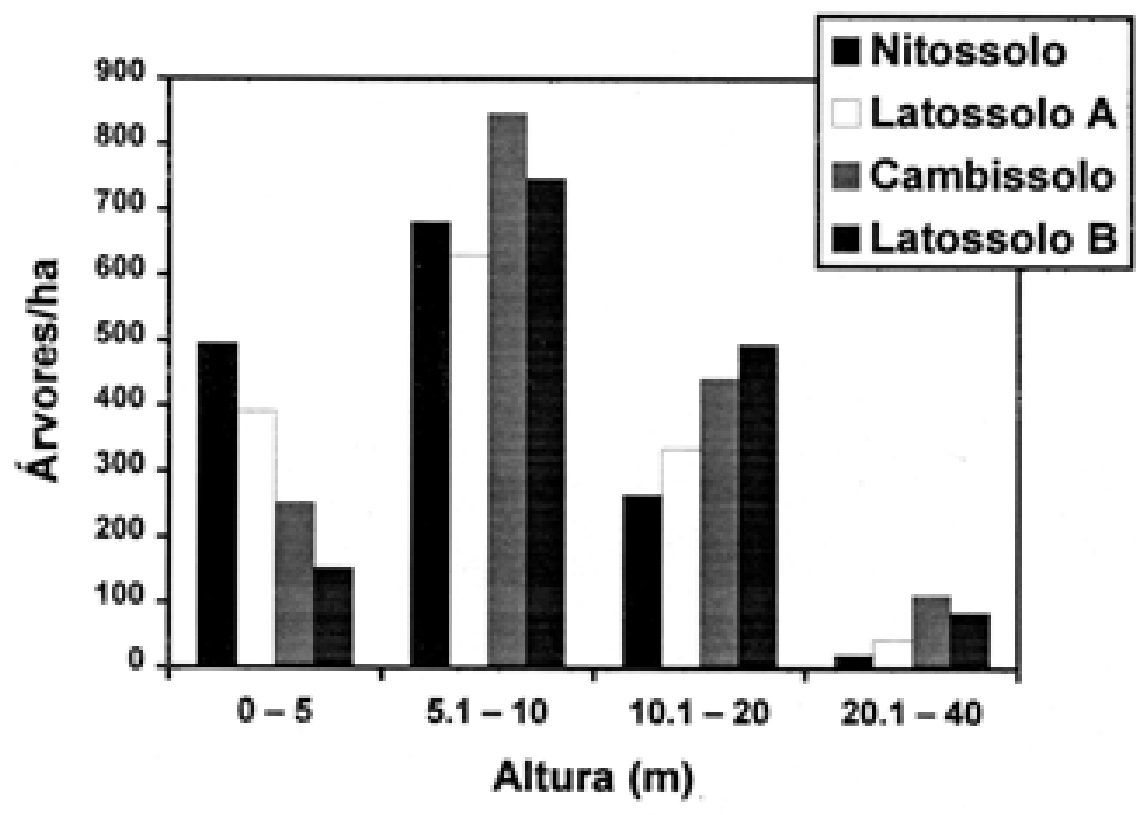

(B)

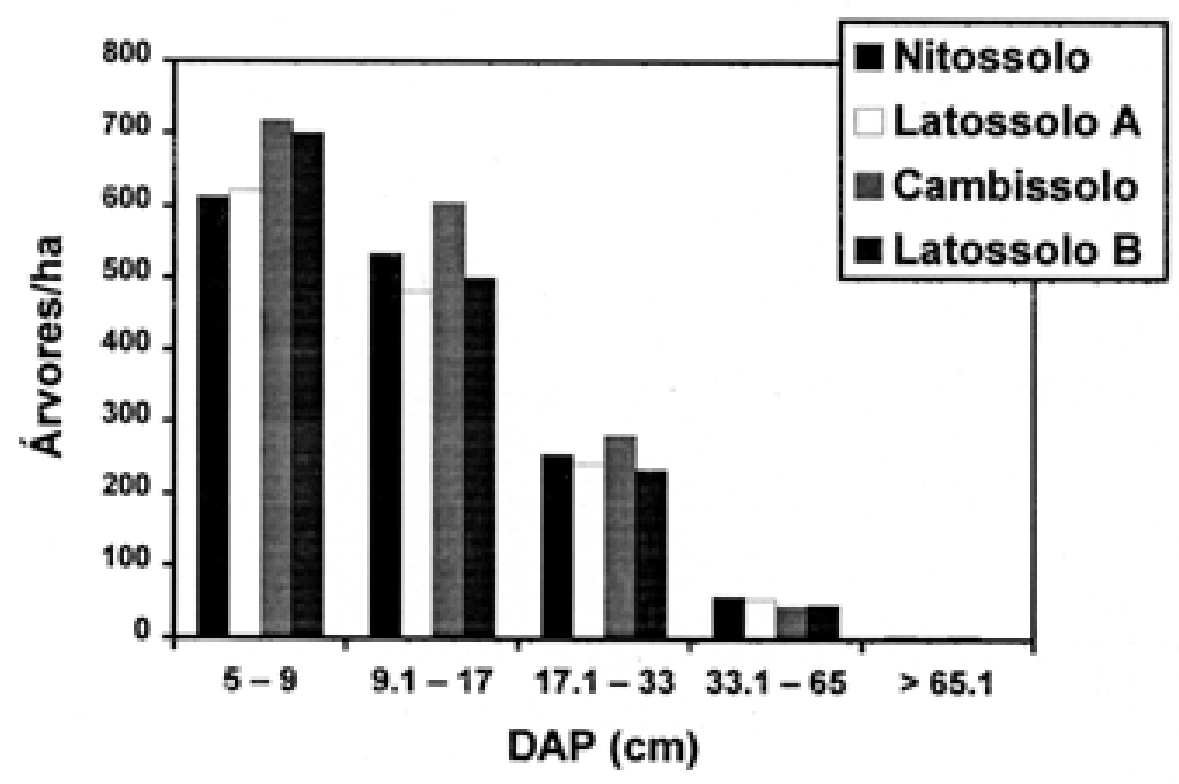

Figura 2. Densidade de árvores por classes de altura (A) e diâmetro (B) nos quatro subgrupos de solos amostrados na Mata da Subestação, Lavras, MG. 
superior, como a Mata da Ilha e a Mata do Galego, com 2683 e 1830 árvores.ha ${ }^{-1}$, respectivamente.

Composição florística e diversidade de espécies - Foram registradas, entre as 3120 árvores amostradas, 175 espécies distribuídas em 115 gêneros e 49 famílias; no levantamento florístico global, esses valores elevam-se a 238 espécies pertencentes a 143 gêneros e 57 famílias (Tab. 3). No fragmento vizinho, a Reserva Florestal da UFLA, Oliveira-Filho et al. (1994a; 1997), encontraram 197 espécies no levantamento florístico global. Contudo, a Reserva da UFLA tem apenas 5,04ha e foi realizado quase um censo (excluindo parte das bordas), com mais de 7000 árvores, o que certamente aproximou muito a estimativa de riqueza do valor real. Daí, pode-se inferir que a Mata da Subestação é, provavelmente, mais rica em espécies que a Reserva da UFLA. Das 238 e 197 espécies registradas pelos levantamentos florísticos globais da Mata da Subestação e Reserva Florestal da UFLA, respectivamente, 145 espécies são comuns aos dois fragmentos, resultando em um coeficiente de similaridade de Jaccard de $50,0 \%$, o que indica uma considerável dissimilaridade florística entre os dois fragmentos, apesar da pequena distância entre os mesmos.

$O$ índice de Shannon, $H^{\prime}=4,19$ nats.indivíduo ${ }^{-1}$, e a equabilidade de Pielou, $\zeta=$ 0,81 , são relativamente altos no contexto de outros levantamentos semelhantes feitos na região (vide Oliveira-Filho et al. 1994c; 1995; Van den Berg \& Oliveira-Filho 2000; Botrel 2001; Rodrigues 2001; Souza 2001) e particularmente superiores aos valores obtidos para Reserva da UFLA: $H=3,605$ nats.indivíduo ${ }^{-1}$ e $J=0,734$ onde a intensidade amostral foi bem mais alta (OliveiraFilho et al. 1994a). Em relação a esta última, é possível que a maior heterogeneidade de relevo e solos da Mata da Subestação contribua fortemente para sua maior diversidade. A Reserva da UFLA tem topografia quase plana e apenas uma subclasse de solo, sendo a distribuição de espécies influenciada basicamente pelo efeito borda e por distúrbios passados (Oliveira-Filho et al. 1997).

Os índices de Shannon, $H$, foram significativamente maiores nos Latossolos A e B que no Cambissolo e Nitossolo (testes de $t$ de $\mathrm{Hu}$ tcheson, $P<0.05)$ e a mesma tendência pode ser observada para a equabilidade de Pielou, $J$ (Tab. 2). É possível que este índice seja o principal responsável pelas diferenças encontradas para $H$ porque seu outro componente, a riqueza de espécies é muito semelhante entre os subgrupos de solos. Uma dominância ecológica (concentração de abundâncias em poucas espécies) menos pronunciada em solos melhor drenados e de menor fertilidade, como são os Latossolos no presente caso, é tendência já encontrada para outras florestas tropicais (Ashton 1990).

Os gêneros com maior riqueza florística foram Ocotea, com 10 espécies; Miconia, com 9; Nectandra, com 7; e Casearia, Eugenia e Zanthoxylum, com 6. Estes seis gêneros contribuíram com $25 \%$ das espécies. As famílias com maior número de espécies foram Fabaceae, com 30; Lauraceae e Myrtaceae, com 22; Melastomataceae com 12; e Euphorbiaceae e Rutaceae, com 10. Estas seis famílias contribuíram com $61 \%$ das espécies. Este perfil florístico é bem típico das florestas semidecíduas montanas da Região do Alto Rio Grande (Oliveira- Filho et al. 1994c, 1995), com a única particularidade da alta riqueza de espécies para Zanthoxylum.

Estrutura da comunidade - Das 10 espécies com maior densidade absoluta (Tab.4); Galipea jasminiflora, Albizia polycephala, Actinostemon concolor, Machaerium stipitatum, Casearia sylvestris, Croton floribundus, Calycorectes acutatus, Cupania vernalis, Platycyamus regnellii e Mollinedia widgrenii; nenhuma pôde ser encontrada entre as dez de maior densidade na Reserva da UFLA, embora todas fossem espécies comuns aos dois fragmentos (Oliveira-Fi- 
Tabela 3. Relação das espécies arbóreas registradas na Mata da Subestação, Lavras, MG, com suas famílias, nomes vernaculares e número das coletas (NC) depositadas no Herbário ESAL pelo coletor E. L. M. Machado (*espécies coletadas fora das parcelas).

\begin{tabular}{|c|c|c|c|}
\hline Famílias e Espécies & Nomes vernaculares & & $\mathrm{NC}$ \\
\hline \multicolumn{4}{|l|}{ Anacardiaceae } \\
\hline Astronium graveolens Jacquin & quebra-machado & & 19 \\
\hline Lithraea molleoides (Vell.) Engler & aroeira-brava & $*$ & 111 \\
\hline Schinus terebinthifolius Raddi & aroeira-vermelha & $*$ & 194 \\
\hline Tapirira guianensis Aublet & pau-pombo, pombeiro & & 215 \\
\hline Tapirira obtusa (Benth.) Mitchell & pombeiro-branco & & 216 \\
\hline \multicolumn{4}{|l|}{ Annonaceae } \\
\hline Annona cacans Warm. & araticum-cagão & & 15 \\
\hline Duguetia lanceolata A.St.-Hil. & pindaúva & & 66 \\
\hline Guatteria nigrescens Mart. & pindaíba-preta & & 92 \\
\hline Rollinia laurifolia Schltdl. & araticum-bravo & & 184 \\
\hline Rollinia sericea (R.E.Fries) R.E.Fries & araticum-do-mato & & 185 \\
\hline Rollinia sylvatica (A.St.-Hil.) Mart. & araticum & & 186 \\
\hline Xylopia brasiliensis Sprengel & pindaíba, pau-mastro & & 228 \\
\hline \multicolumn{4}{|l|}{ Apocynaceae } \\
\hline Aspidosperma parvifolium A.DC. & guatambu-amarelo & $*$ & 16 \\
\hline Aspidosperma ramiflorum Müll.Arg. & cabo-de-machado & & 17 \\
\hline Aspidosperma spruceanum Benth. & perobão & & 18 \\
\hline \multicolumn{4}{|l|}{ Aquifoliaceae } \\
\hline Ilex cerasifolia Reissek & congonha & & 100 \\
\hline \multicolumn{4}{|l|}{ Araliaceae } \\
\hline Dendropanax cuneatus (DC.) & maria-mole & & 62 \\
\hline \multicolumn{4}{|l|}{ Decne \& Planchon } \\
\hline Schefflera longepetiolata (E.Marchal) D.Frodin & mandiocão & & 193 \\
\hline \multicolumn{4}{|l|}{ Arecaceae } \\
\hline Euterpe edulis Mart. & palmito & & 79 \\
\hline Syagrus romanzoffiana (Cham.) & jerivá & & 211 \\
\hline \multicolumn{4}{|l|}{ Glassman } \\
\hline \multicolumn{4}{|l|}{ Asteraceae } \\
\hline Gochnatia paniculata (Less.) Cabrera & candeia-podre & $*$ & 86 \\
\hline Piptocarpha macropoda Baker & vassoura-preta & & 170 \\
\hline Vernonanthura diffusa (Less.) & vassourão & $*$ & 223 \\
\hline H.Robinson & & & \\
\hline \multicolumn{4}{|l|}{ Bignoniaceae } \\
\hline Cybistax antisyphillitica Mart. & cinco-chagas & & 59 \\
\hline Jacaranda macrantha Cham. & caroba-do-mato & & 106 \\
\hline Tabebuia serratifolia (Vahl) Nichols & ipê-amarelo & $*$ & 213 \\
\hline Tabebuia vellosoi Toledo & ipê-amarelo & * & 214 \\
\hline \multicolumn{4}{|l|}{ Boraginaceae } \\
\hline Cordia ecalyculata Vell. & café-de-bugre & & 52 \\
\hline Cordia magnoliifolia Cham. & jaguará-muru & & 53 \\
\hline Cordia sellowiana Cham. & chá-de-bugre & & 54 \\
\hline \multicolumn{4}{|l|}{ Burseraceae } \\
\hline Protium widgrenii Engler & almecega-cascuda & & 173 \\
\hline \multicolumn{4}{|l|}{ Canellaceae } \\
\hline Cinnamodendron dinisii Schwacke & casca-d'anta & $*$ & 45 \\
\hline \multicolumn{4}{|l|}{ Cecropiaceae } \\
\hline Cecropia glaziovii Snethl. & embaúba & & 38 \\
\hline Cecropia pachystachya Trécul & embaúba & $*$ & 39 \\
\hline
\end{tabular}


Tabela 3. (continuação).

\begin{tabular}{|c|c|c|c|}
\hline Famílias e Espécies & Nomes vernaculares & & $\mathrm{NC}$ \\
\hline \multicolumn{4}{|l|}{ Celastraceae } \\
\hline Maytenus ilicifolia Mart. & coração-de-bugre & & 124 \\
\hline Maytenus glazioviana Loesen & cafezinho & & 125 \\
\hline Salacia elliptica (Mart.) G.Don. & bacupari & & 189 \\
\hline \multicolumn{4}{|l|}{ Celtidaceae } \\
\hline Celtis iguanaea (Jacquin) Sargent & esporão-de-galo & * & 41 \\
\hline Celtis pubescens Sprengel & esporão-de-galo & * & 42 \\
\hline \multicolumn{4}{|l|}{ Chrysobalanaceae } \\
\hline Hirtella hebeclada Moric. & araçá-da-serra & * & 97 \\
\hline \multicolumn{4}{|l|}{ Clusiaceae } \\
\hline Garcinia gardneriana (Planchon \& Triana) & bacupari & & 85 \\
\hline \multicolumn{4}{|l|}{ Zappi } \\
\hline Vismia brasiliensis Choisy & pau-de-lacre & & 224 \\
\hline \multicolumn{4}{|l|}{ Combretaceae } \\
\hline Terminalia glabrescens Mart. & mirindiba & $*$ & 217 \\
\hline \multicolumn{4}{|l|}{ Connaraceae } \\
\hline Connarus regnellii G.Schelenb. & camboatã-da-serra & & 50 \\
\hline \multicolumn{4}{|l|}{ Cunoniaceae } \\
\hline Lamanonia ternata Vell. & cedrilho & * & 108 \\
\hline \multicolumn{4}{|l|}{ Ebenaceae } \\
\hline Diospyros hispida A.DC. & coco-de-bugre & * & 64 \\
\hline Diospyros inconstans Jacquin & marmelinho-do-mato & & 65 \\
\hline \multicolumn{4}{|l|}{ Elaeocarpaceae } \\
\hline Sloanea monosperma Vell. & ouriceiro & & 202 \\
\hline \multicolumn{4}{|l|}{ Erythroxylaceae } \\
\hline Erythroxylum ambiguum Peyr. & fruta-de-juriti & $*$ & 69 \\
\hline Erythroxylum citrifolium A.St.-Hil. & fruta-de-pombo & $*$ & 70 \\
\hline Erythroxylum deciduum A.St.-Hil. & fruta-de-juriti & & 71 \\
\hline \multicolumn{4}{|l|}{ Euphorbiaceae } \\
\hline Actinostemon concolor (Sprengel) Müll.Arg. & laranjeira-do-mato & & 2 \\
\hline Alchornea glandulosa Poepp. \& Endl. & tanheiro & $*$ & 5 \\
\hline Alchornea triplinervea (Sprengel) Müll.Arg. & tapiá-vermelho & $*$ & 6 \\
\hline Croton floribundus Sprengel & capichingui & & 56 \\
\hline Hyeronima ferruginea Müll.Arg. & sangue-de-boi & $*$ & 98 \\
\hline Maprounea guianensis Aublet & vaquinha, marmeleiro & & 122 \\
\hline Pera glabrata (Schott) Poepp. & pau-de-tamanco & & 167 \\
\hline Sapium glandulosum (L.) Morong & leiteiro & $*$ & 190 \\
\hline Sapium obovatum Klotzsch & leiteirinho & $*$ & 191 \\
\hline Savia dictyocarpa (Müll.Arg.) Müll.Arg. & guaraiúva & $*$ & 192 \\
\hline \multicolumn{4}{|l|}{ Fabacea e Caesalpinioideae } \\
\hline Bauhinia longifolia (Bongard) Steudel & pata-de-vaca & & 21 \\
\hline Cassia ferruginea (Schrad.) Schrad. & canafístula & & 37 \\
\hline Copaifera langsdorffii Desf. & óleo-de-copaíba & & 51 \\
\hline Hymenaea courbaril L. & jatobá, jataí & & 99 \\
\hline Peltogyne angustiflora Ducke & guarabu & & 165 \\
\hline Peltophorum dubium (Sprengel) Taub. & canafístula, faveira & & 166 \\
\hline Sclerolobium rugosum Mart. & angá & $*$ & 195 \\
\hline Senna macranthera (Vell.) Irwin \& Barneby & amarelinho, fedegoso & & 197 \\
\hline Senna multijuga (L.C.Rich.) Irwin \& Barneby & cássia-verrugosa & $*$ & 198 \\
\hline \multicolumn{4}{|l|}{ Fabaceae Faboideae } \\
\hline Andira fraxinifolia Benth. & angelim & $*$ & 13 \\
\hline Dalbergia villosa (Benth.) Benth. & milho-torrado & & 60 \\
\hline
\end{tabular}


Tabela 3. (continuação).

\begin{tabular}{|c|c|c|c|}
\hline Famílias e Espécies & Nomes vernaculares & & $\mathrm{NC}$ \\
\hline Lonchocarpus cultratus (Vell.) & embira-de-sapo & & 112 \\
\hline \multicolumn{4}{|l|}{ Az.Tozzi \& H.C.Lima } \\
\hline Lonchocarpus muehlbergianus Hassler & feijão & & 113 \\
\hline Machaerium brasiliense Vogel & jacarandá & & 116 \\
\hline Machaerium hirtum (Vell.) Stellfeld & adolfo & & 117 \\
\hline Machaerium nictitans (Vell.) Benth. & jacarandá-bico-de-pato & & 118 \\
\hline Machaerium stipitatum (DC.) Vogel & jacarandá & & 119 \\
\hline Machaerium villosum Vogel & jacarandá-mineiro & & 120 \\
\hline Ormosia arborea (Vell.) Harms & olho-de-cabra & & 163 \\
\hline Platycyamus regnellii Benth. & pau-pereira & & 171 \\
\hline Platypodium elegans Vogel & jacarandá-canzil & $*$ & 172 \\
\hline \multicolumn{4}{|l|}{ Fabaceae Mimosoideae } \\
\hline Acacia glomerosa Benth. & espinheiro & & 1 \\
\hline Albizia polycephala (Benth.) Killip & farinha-seca & & 4 \\
\hline Anadenanthera colubrina (Vell.) Brenan & angico-branco & & 12 \\
\hline Inga cylindrica (Vell.) Mart. & ingá-feijão & & 101 \\
\hline Inga ingoides (Rich.) Willd. & ingá-tripa & $*$ & 102 \\
\hline Inga marginata Willd. & ingaí & & 103 \\
\hline Inga striata Benth. & ingá & & 104 \\
\hline Leucochloron incuriale (Vell.) & angico-cascudo & & 110 \\
\hline \multicolumn{4}{|l|}{ Barneby \& Grimes } \\
\hline Piptadenia gonoacantha (Mart.) Macbr. & pau-jacaré & & 169 \\
\hline \multicolumn{4}{|l|}{ Flacourtiaceae } \\
\hline Casearia arborea (L.C.Rich.) Urban & espeto-verde & & 31 \\
\hline Casearia decandra Jacquin & cambroé & & 32 \\
\hline Casearia gossypiosperma Briquet & lingua-de-tiú & & 33 \\
\hline Casearia lasiophylla Eichler & erva-de-lagarto & & 34 \\
\hline Casearia obliqua Sprengel & guaçatunga & & 35 \\
\hline Casearia sylvestris Swartz & guaçatonga & & 36 \\
\hline Xylosma ciliatifolium (Clos) Eichler & espinho-de-judeu & & 229 \\
\hline Xylosma prockia (Turcz.) Turcz. & espinheiro & & 230 \\
\hline \multicolumn{4}{|l|}{ Icacinaceae } \\
\hline Citronella paniculata (Mart.) Howard & erva-de-anta, assis & & 47 \\
\hline \multicolumn{4}{|l|}{ Lacistemataceae } \\
\hline Lacistema hasslerianum Chodat & espeto & $*$ & 107 \\
\hline \multicolumn{4}{|l|}{ Lauraceae } \\
\hline Aniba firmula (Nees \& Mart.) Mez & canela-de-cheiro & & 14 \\
\hline Cinnamomum glaziovii (Mez) Vattimo & guaruva & & 46 \\
\hline Cryptocarya aschersoniana $\mathrm{Mez}$ & canela-batalha & & 57 \\
\hline Endlicheria paniculata (Sprengel) Macbr. & canela-do-brejo & & 67 \\
\hline Nectandra cissiflora Nees & canela-fedida & & 146 \\
\hline Nectandra grandiflora Nees & canela-sassafrás & & 147 \\
\hline Nectandra lanceolata Nees & canela-cedro & & 148 \\
\hline Nectandra megapotamica (Sprengel) Mez & canela-fedorenta & & 149 \\
\hline Nectandra nitidula Nees & canela-do-córrego & & 150 \\
\hline Nectandra oppositifolia Nees & canela-ferrugem & & 151 \\
\hline Nectandra warmingii Meisner & canela & & 152 \\
\hline Ocotea aciphylla (Nees) Mez & canela-amarela & & 153 \\
\hline Ocotea odorifera (Nees) Mez & canelinha & $*$ & 154 \\
\hline Ocotea corymbosa (Meisner) Mez & canela-bosta & & 155 \\
\hline Ocotea diospyrifolia (Meisner) Mez & louro-amarelo & & 156 \\
\hline Ocotea elegans $\mathrm{Mez}$ & sassafraz-do-campo & & 157 \\
\hline
\end{tabular}


Tabela 3. (continuação).

\begin{tabular}{|c|c|c|c|}
\hline Famílias e Espécies & Nomes vernaculares & & $\mathrm{NC}$ \\
\hline Ocotea glaziovii Mez & canela-preta & & 158 \\
\hline Ocotea laxa $(\mathrm{Nees}) \mathrm{Mez}$ & canelinha & & 159 \\
\hline Ocotea odorifera (Vell.) Rohwer & canela-sassafrás & & 160 \\
\hline Ocotea variabilis (Nees) Mez & canela-do-mato & * & 161 \\
\hline Ocotea velutina (Nees) Rohwer & canela-peluda & & 162 \\
\hline Persea pyrifolia Nees \& Mart. & maçaranduba & & 168 \\
\hline \multicolumn{4}{|l|}{ Lecythidaceae } \\
\hline Cariniana estrellensis (Raddi) Kuntze & jequitibá-branco & & 29 \\
\hline Cariniana legalis (Mart.) Kuntze & jequitibá-rosa & & 30 \\
\hline \multicolumn{4}{|l|}{ Malpighiaceae } \\
\hline Byrsonima laxiflora Griseb. & murici & & 23 \\
\hline Heteropterys byrsonimifolia A.Juss. & murici-de-rama & $*$ & 96 \\
\hline \multicolumn{4}{|l|}{ Malvaceae } \\
\hline Eriotheca candolleana (K.Schum.) A.Robyns & pau-de-paina & & 68 \\
\hline Guazuma ulmifolia Lam. & pau-de-motamba & & 93 \\
\hline Helicteres ovata Lam. & saca-rolha & & 95 \\
\hline Luehea divaricata Mart. \& Zucc. & açoita-cavalo & & 114 \\
\hline Luehea grandiflora Mart. \& Zucc. & açoita-cavalo & & 115 \\
\hline \multicolumn{4}{|l|}{ Melastomataceae } \\
\hline Leandra scabra DC. & pixirica & $*$ & 109 \\
\hline Miconia albicans Triana & pixiriquinha & & 127 \\
\hline Miconia argyrophylla DC. & casca-de-arroz & & 128 \\
\hline Miconia chartacea Triana & pexiriquinha & $*$ & 129 \\
\hline Miconia cinnamomifolia (DC.) Naudin & casca-de-arroz & & 130 \\
\hline Miconia latecrenata (DC.) Naudin & jacatirão, jacatirão-açu & $*$ & 131 \\
\hline Miconia ligustroides (DC.) Naudin & jacatirão & $*$ & 132 \\
\hline Miconia minutiflora (Bonpl.) Triana & jacatirão & $*$ & 251 \\
\hline Miconia pepericarpa DC. & carvãozinho-vermelho & $*$ & 133 \\
\hline Miconia pusilliflora (DC.) Triana & jacatirão-açu & $*$ & 134 \\
\hline Miconia trianae Cogn. & pixirica & $*$ & 135 \\
\hline Tibouchina sellowiana (Cham.) Cogn. & quaresmão & & 218 \\
\hline Tibouchina stenocarpa (DC.) Cogn. & cuiupeva & & 219 \\
\hline \multicolumn{4}{|l|}{ Meliaceae } \\
\hline Cabralea canjerana (Vell.) Mart. & cangerana & & 24 \\
\hline Cedrela fissilis Vell. & cedro & & 40 \\
\hline Guarea kunthiana A.Juss. & peloteira & & 90 \\
\hline Guarea macrophylla Vahl. & marinheiro & & 91 \\
\hline Trichilia emarginata (Turcz.) C.DC. & catiguá & $*$ & 220 \\
\hline Trichilia lepidota Mart. & catiguá & & 221 \\
\hline Trichilia pallida Swartz & catiguá & $*$ & 222 \\
\hline \multicolumn{4}{|l|}{ Memecylaceae } \\
\hline Mouriri glazioviana Cogn. & cabelo-de-negro & & 137 \\
\hline \multicolumn{4}{|l|}{ Monimiaceae } \\
\hline Mollinedia widgrenii A.DC. & pimenteira-brava & & 136 \\
\hline \multicolumn{4}{|l|}{ Moraceae } \\
\hline Ficus gomelleira Kunth \& Bouché & gameleira & $*$ & 80 \\
\hline Ficus insipida Willd. & figueira-do-brejo & & 81 \\
\hline Ficus mexiae Standley & figueira-mata-pau & & 82 \\
\hline Ficus tomentella (Miq.) Miq. & gameleira & $*$ & 83 \\
\hline Maclura tinctoria (L.) D.Don. & amoreira & & 121 \\
\hline Sorocea bonplandii (Baillon) W.Burger & canxim & & 207 \\
\hline
\end{tabular}


Tabela 3. (continuação).

\begin{tabular}{|c|c|c|c|}
\hline Famílias e Espécies & Nomes vernaculares & & $\mathrm{NC}$ \\
\hline \multicolumn{4}{|l|}{ Myrsinaceae } \\
\hline Myrsine lancifolia Mart. & capororoca-lisa & & 144 \\
\hline Myrsine umbellata Mart. & pororoca-branca & & 145 \\
\hline \multicolumn{4}{|l|}{ Myrtaceae } \\
\hline Blepharocalyx salicifolius (Kunth) O.Berg & murta, cambuí & & 22 \\
\hline Calycorectes acutatus (Miq.) Toledo & araçá-da-serra & & 25 \\
\hline Calyptranthes clusiifolia (Miq.) O.Berg & orelha-de-burro & & 26 \\
\hline Calyptranthes grandifolia O.Berg & jambo-do-mato & $*$ & 27 \\
\hline Campomanesia guazumifolia (Cambess.) & sete-casacas & & 28 \\
\hline \multicolumn{4}{|l|}{ O.Berg } \\
\hline Eugenia cerasiflora Miq. & cereja & & 73 \\
\hline Eugenia excelsa Cambess. & guamirim & $*$ & 74 \\
\hline Eugenia florida DC. & pimenteira & & 75 \\
\hline Eugenia handroana D.Legrand & cereja-do-mato & & 76 \\
\hline Eugenia pyriformis Cambess. & uvaia & & 77 \\
\hline Eugenia sp. & cereja & & 78 \\
\hline Gomidesia affinis (Cambess.) D.Legrand & perta-güela & & 87 \\
\hline Myrcia fallax (Rich.) DC. & guamirim & & 138 \\
\hline Myrcia rostrata DC. & piúna, folha-miúda & & 139 \\
\hline Myrcia tomentosa (Aublet) DC. & goiabão, goiaba-brava & & 140 \\
\hline Myrcia velutina O.Berg & piúna & $*$ & 141 \\
\hline Myrcia venulosa DC. & guamirim-do-campo & $*$ & 237 \\
\hline Myrciaria cauliflora (Mart.) O.Berg & jaboticabeira & * & 142 \\
\hline Myrciaria floribunda (West) O.Berg & jaboticaba-do-mato & & 143 \\
\hline Psidium cattleyanum Sabine & araçá-do-mato & & 175 \\
\hline Psidium rufum Mart. & guavirova & & 176 \\
\hline Siphoneugena densiflora O.Berg & cravinho & & 201 \\
\hline \multicolumn{4}{|l|}{ Nyctaginaceae } \\
\hline Guapira graciliflora (Schmidt) Lundell & joão-mole & & 88 \\
\hline Guapira hirsuta (Choisy) Lundell & maria-mole & & 89 \\
\hline \multicolumn{4}{|l|}{ Ochnaceae } \\
\hline Ouratea semiserrata (Mart. \& Nees) Engler & farinha-seca & & 164 \\
\hline \multicolumn{4}{|l|}{ Olacaceae } \\
\hline Heisteria silvianii Schwacke & bico-de-mulata & & 94 \\
\hline \multicolumn{4}{|l|}{ Phytolaccaceae } \\
\hline Seguieria langsdorffii Moq. & agulheiro, limão-bravo & & 196 \\
\hline \multicolumn{4}{|l|}{ Polygonaceae } \\
\hline Coccoloba warmingii Meisner & cabaçu & & 48 \\
\hline \multicolumn{4}{|l|}{ Proteaceae } \\
\hline Roupala longepetiolata Pohl & carne-de-vaca & & 187 \\
\hline Roupala montana Aublet & carne-de-vaca & & 188 \\
\hline \multicolumn{4}{|l|}{ Rhamnaceae } \\
\hline Colubrina glandulosa Perkins & sobrasil & & 49 \\
\hline Rhamnidium elaeocarpum Reissek & tarumaí & & 182 \\
\hline Rhamnus sphaerosperma Swartz & saguaraji-vermelho & $*$ & 183 \\
\hline \multicolumn{4}{|l|}{ Rosaceae } \\
\hline Prunus brasiliensis (Cham. \& Schltd1.) D.Dietr. & pessegueiro-bravo & & 174 \\
\hline \multicolumn{4}{|l|}{ Rubiaceae } \\
\hline Alibertia concolor (Cham.) K.Schum. & marmelada & & 7 \\
\hline Amaioua guianensis Aublet & marmelada & & 11 \\
\hline Coutarea hexandra (Jacquin) K.Schum. & quina & & 55 \\
\hline Ixora warmingii Müll.Arg. & café-bravo & & 105 \\
\hline
\end{tabular}


Tabela 3. (continuação).

\begin{tabular}{|c|c|c|c|}
\hline Famílias e Espécies & Nomes vernaculares & & $\mathrm{NC}$ \\
\hline Psychotria deflexa DC. & pau-de-espeto & & 177 \\
\hline Psychotria sessilis (Vell.) Müll.Arg. & matadeira & $*$ & 178 \\
\hline Randia nitida (Kunth) DC. & limão-bravo & * & 181 \\
\hline \multicolumn{4}{|l|}{ Rutaceae } \\
\hline Balfourodendron riedelianum (Engler) Engler & pau-marfim & & 20 \\
\hline Esenbeckia febrifuga (A.St.-Hil.) A.Juss. & grumarim & $*$ & 72 \\
\hline Galipea jasminiflora (A.St.-Hil.) Engler & três-folhas & & 84 \\
\hline Metrodorea stipularis Mart. & chupa-ferro & & 126 \\
\hline Zanthoxylum caribaeum Lam. & mamica-preta & & 231 \\
\hline Zanthoxylum fagara (L.) Sargent & mamica-de-porca & & 232 \\
\hline Zanthoxylum monogynum A.St.-Hil. & mamica-de-porca & & 233 \\
\hline Zanthoxylum rhoifolium Lam. & mamica-de-porca & & 234 \\
\hline Zanthoxylum riedelianum Engler & mamica-cascuda & & 235 \\
\hline Zanthoxylum petiolare A.St.-Hil \& Tul. & mamica-preta & & 236 \\
\hline \multicolumn{4}{|l|}{ Sapindaceae } \\
\hline Allophylus edulis (A.St.-Hil.) Radlk. & baga-de-morcego & & 8 \\
\hline Allophylus semidentatus (Miq.) Radlk. & fruta-de-faraó & & 9 \\
\hline Cupania vernalis Cambess. & camboatá & & 58 \\
\hline Diatenopteryx sorbifolia Radlk. & cansa-crioulo & & 63 \\
\hline Matayba elaeagnoides Radlk. & pau-de-pombo & & 123 \\
\hline \multicolumn{4}{|l|}{ Sapotaceae } \\
\hline $\begin{array}{l}\text { Chrysophyllum gonocarpum } \\
\text { (Mart. \& Eichler) Engler }\end{array}$ & aguaí, caxeta & & 43 \\
\hline $\begin{array}{l}\text { Chrysophyllum marginatum } \\
\text { (Hooker \& Arnot) Radlk. }\end{array}$ & aguaí, aranhão & & 44 \\
\hline \multicolumn{4}{|l|}{ Siparunaceae } \\
\hline Siparuna cujabana (Mart.) A.DC. & pau-limão & $*$ & 200 \\
\hline Siparuna guianensis Aublet & negraminia, capitú & & 199 \\
\hline \multicolumn{4}{|l|}{ Solanaceae } \\
\hline Solanum cernuum Vell. & panacéia & $*$ & 203 \\
\hline Solanum granuloso-leprosum Dunal & gravitinga & * & 204 \\
\hline Solanum leucodendron Sendt. & folha-de-prata & & 205 \\
\hline Solanum pseudoquina A.St.-Hil. & joá-de-árvore & & 206 \\
\hline \multicolumn{4}{|l|}{ Styracaceae } \\
\hline Styrax camporus Pohl & fruta-de-pomba & & 208 \\
\hline Styrax ferrugineus Nees \& Mart. & benjoeiro & & 209 \\
\hline Styrax latifolius Pohl & salgueiro & & 210 \\
\hline \multicolumn{4}{|l|}{ Symplocaceae } \\
\hline Symplocos pubescens Klotzsch & sete-sangrias & $*$ & 212 \\
\hline \multicolumn{4}{|l|}{ Thymelaeaceae } \\
\hline Daphnopsis fasciculata (Meisner) Nevling & imbira-vermelha & & 61 \\
\hline \multicolumn{4}{|l|}{ Verbenaceae } \\
\hline Aegiphila sellowiana Cham. & pau-de-tamanco & $*$ & 3 \\
\hline Aloysia virgata (Ruiz \& Pavón) A.Juss. & pau-lixa & * & 10 \\
\hline Vitex cymosa Bert. & maria-preta & $*$ & 225 \\
\hline Vitex polygama Cham. & maria-preta & * & 226 \\
\hline \multicolumn{4}{|l|}{ Vochysiaceae } \\
\hline Qualea cordata Sprengel & pau-terra & & 179 \\
\hline Qualea multiflora Mart. & pau-terra & $*$ & 180 \\
\hline Vochysia tucanorum Mart. & pau-de-tucano & $*$ & 227 \\
\hline
\end{tabular}


Tabela 4. Relação das espécies arbóreas amostradas na Mata da Subestação, Lavras, MG, com seus respectivos parâmetros quantitativos: $\mathrm{N}$ = número de indivíduos; $\mathrm{P}=$ número de parcelas onde ocorre; $\mathrm{AB}$ = área basal total; Amd = altura média; $\mathrm{Amx}=$ altura máxima; $\mathrm{DA}=$ densidade absoluta; $\mathrm{DoA}=$ dominância absoluta; $\mathrm{DR}=$ densidade relativa; $\mathrm{DoR}=$ dominância relativa; $\mathrm{VC}=$ valor de cobertura. Espécies ordenadas por $\mathrm{VC}$ decrescente.

\begin{tabular}{|c|c|c|c|c|c|c|c|c|c|c|}
\hline Espécie & $\mathrm{N}$ & $\mathrm{P}$ & $\begin{array}{l}\mathrm{AB} \\
\left(\mathrm{m}^{2}\right)\end{array}$ & $\begin{array}{l}\text { Amd } \\
(\mathrm{m})\end{array}$ & $\begin{array}{c}\operatorname{Amx} \\
(\mathrm{m})\end{array}$ & $\begin{array}{c}\text { DA } \\
\left(\mathrm{n}^{\circ} \mathrm{ha}^{-1}\right)\end{array}$ & $\begin{array}{c}\text { DoA } \\
\left(\mathrm{m}^{2} \mathrm{ha}^{-1}\right)\end{array}$ & $\begin{array}{l}\text { DR } \\
(\%)\end{array}$ & $\begin{array}{l}\text { DoR } \\
(\%)\end{array}$ & $\mathrm{VC}$ \\
\hline Croton floribundus & 108 & 31 & 4,071 & 12,5 & 30,0 & 51,9 & 1,957 & 3,46 & 7,18 & 10,64 \\
\hline Galipea jasminiflora & 217 & 32 & 1,181 & 6,0 & 14,0 & 104,3 & 0,568 & 6,96 & 2,08 & 9,04 \\
\hline Piptadenia gonoacantha & 59 & 24 & 4,003 & 13,8 & 26,5 & 28,4 & 1,925 & 1,89 & 7,07 & 8,96 \\
\hline Albizia polycephala & 152 & 43 & 2,238 & 10,7 & 22,0 & 73,1 & 1,076 & 4,87 & 3,95 & 8,82 \\
\hline Actinostemon concolor & 152 & 32 & 1,217 & 5,9 & 12,0 & 73,1 & 0,585 & 4,87 & 2,15 & 7,02 \\
\hline Machaerium stipitatum & 128 & 31 & 1,371 & 8,6 & 27,0 & 61,5 & 0,659 & 4,10 & 2,42 & 6,52 \\
\hline Platycyamus regnellii & 93 & 34 & 1,850 & 12,5 & 30,0 & 44,7 & 0,889 & 2,98 & 3,27 & 6,25 \\
\hline Casearia sylvestris & 113 & 36 & 1,087 & 7,5 & 16,0 & 54,3 & 0,522 & 3,62 & 1,92 & 5,54 \\
\hline Calycorectes acutatus & 103 & 35 & 1,051 & 9,0 & 30,0 & 49,5 & 0,506 & 3,30 & 1,86 & 5,16 \\
\hline Ocotea corymbosa & 52 & 28 & 1,782 & 13,7 & 26,0 & 25,0 & 0,857 & 1,67 & 3,15 & 4,82 \\
\hline Cupania vernalis & 95 & 41 & 0,964 & 7,7 & 16,0 & 45,7 & 0,463 & 3,04 & 1,70 & 4,74 \\
\hline Coccoloba warmingii & 79 & 18 & 1,250 & 11,5 & 30,0 & 38,0 & 0,601 & 2,53 & 2,21 & 4,74 \\
\hline Colubrina glandulosa & 34 & 14 & 1,939 & 14,5 & 27,0 & 16,3 & 0,932 & 1,09 & 3,42 & 4,51 \\
\hline Mollinedia widgrenii & 85 & 38 & 1,007 & 7,6 & 16,0 & 40,9 & 0,484 & 2,72 & 1,78 & 4,50 \\
\hline Ixora warmingii & 78 & 36 & 1,060 & 8,4 & 17,0 & 37,5 & 0,509 & 2,50 & 1,87 & 4,37 \\
\hline Myrcia fallax & 82 & 28 & 0,947 & 10,0 & 27,0 & 39,4 & 0,455 & 2,63 & 1,67 & 4,30 \\
\hline Miconia cinnamomifolia & 24 & 10 & 1,970 & 20,3 & 30,0 & 11,5 & 0,947 & 0,77 & 3,48 & 4,25 \\
\hline Bauhinia longifolia & 82 & 38 & 0,746 & 7,5 & 23,0 & 39,4 & 0,359 & 2,63 & 1,32 & 3,95 \\
\hline Rollinia sylvatica & 58 & 22 & 1,143 & 12,1 & 25,0 & 27,9 & 0,550 & 1,86 & 2,02 & 3,88 \\
\hline Roupala montana & 63 & 30 & 0,910 & 7,8 & 22,0 & 30,3 & 0,438 & 2,02 & 1,61 & 3,63 \\
\hline Eugenia florida & 71 & 18 & 0,702 & 6,6 & 11,0 & 34,1 & 0,338 & 2,28 & 1,24 & 3,52 \\
\hline Nectandra oppositifolia & 38 & 22 & 1,175 & 11,3 & 22,0 & 18,3 & 0,565 & 1,22 & 2,07 & 3,29 \\
\hline Inga striata & 44 & 29 & 1,026 & 13,3 & 22,0 & 21,2 & 0,493 & 1,41 & 1,81 & 3,22 \\
\hline Matayba elaeagnoides & 46 & 21 & 0,958 & 11,0 & 21,5 & 22,1 & 0,461 & 1,47 & 1,69 & 3,16 \\
\hline Guazuma ulmifolia & 37 & 19 & 1,029 & 9,6 & 18,0 & 17,8 & 0,495 & 1,19 & 1,82 & 3,01 \\
\hline Tapirira obtusa & 35 & 23 & 0,997 & 12,2 & 30,0 & 16,8 & 0,479 & 1,12 & 1,76 & 2,88 \\
\hline Copaifera langsdorffii & 20 & 13 & 0,953 & 12,5 & 25,0 & 9,6 & 0,458 & 0,64 & 1,68 & 2,32 \\
\hline Cabralea canjerana & 19 & 14 & 0,959 & 13,2 & 27,0 & 9,1 & 0,461 & 0,61 & 1,69 & 2,30 \\
\hline Vismia brasiliensis & 29 & 19 & 0,690 & 12,4 & 21,5 & 13,9 & 0,332 & 0,93 & 1,22 & 2,15 \\
\hline Miconia argyrophylla & 17 & 10 & 0,890 & 13,5 & 30,0 & 8,2 & 0,428 & 0,54 & 1,57 & 2,11 \\
\hline Cariniana legalis & 14 & 10 & 0,817 & 13,7 & 28,0 & 6,7 & 0,393 & 0,45 & 1,44 & 1,89 \\
\hline Cariniana estrellensis & 18 & 16 & 0,739 & 11,1 & 25,0 & 8,7 & 0,355 & 0,58 & 1,30 & 1,88 \\
\hline Casearia obliqua & 37 & 17 & 0,311 & 9,4 & 17,0 & 17,8 & 0,149 & 1,19 & 0,55 & 1,74 \\
\hline Rollinia laurifolia & 24 & 17 & 0,470 & 10,6 & 20,0 & 11,5 & 0,226 & 0,77 & 0,83 & 1,60 \\
\hline Dalbergia villosa & 17 & 11 & 0,593 & 12,0 & 23,0 & 8,2 & 0,285 & 0,54 & 1,05 & 1,59 \\
\hline Luehea grandiflora & 21 & 10 & 0,515 & 10,2 & 23,0 & 10,1 & 0,247 & 0,67 & 0,91 & 1,58 \\
\hline Machaerium villosum & 21 & 15 & 0,470 & 8,7 & 22,0 & 10,1 & 0,226 & 0,67 & 0,83 & 1,50 \\
\hline Myrciaria floribunda & 34 & 19 & 0,218 & 5,6 & 20,0 & 16,3 & 0,105 & 1,09 & 0,39 & 1,48 \\
\hline Heisteria silvianii & 31 & 17 & 0,260 & 8,0 & 17,0 & 14,9 & 0,125 & 0,99 & 0,46 & 1,45 \\
\hline Guapira hirsuta & 31 & 22 & 0,185 & 7,5 & 20,0 & 14,9 & 0,089 & 0,99 & 0,33 & 1,32 \\
\hline Rollinia sericea & 19 & 12 & 0,395 & 10,1 & 18,0 & 9,1 & 0,190 & 0,61 & 0,70 & 1,31 \\
\hline Ocotea laxa & 21 & 15 & 0,163 & 5,3 & 8,5 & 10,1 & 0,078 & 0,67 & 0,29 & 0,96 \\
\hline Mouriri glazioviana & 17 & 10 & 0,241 & 9,0 & 30,0 & 8,2 & 0,116 & 0,54 & 0,42 & 0,96 \\
\hline Annona cacans & 8 & 7 & 0,392 & 13,2 & 26,0 & 3,8 & 0,188 & 0,26 & 0,69 & 0,95 \\
\hline Maclura tinctoria & 17 & 13 & 0,192 & 8,5 & 16,0 & 8,2 & 0,092 & 0,54 & 0,34 & 0,88 \\
\hline Cryptocarya aschersoniana & 11 & 8 & 0,287 & 14,0 & 22,0 & 5,3 & 0,138 & 0,35 & 0,51 & 0,86 \\
\hline Connarus regnellii & 14 & 10 & 0,199 & 6,7 & 12,0 & 6,7 & 0,096 & 0,45 & 0,35 & 0,80 \\
\hline
\end{tabular}


Variáveis ambientais e a distribuição de espécies arbóreas.

Tabela 4. (continuação).

\begin{tabular}{|c|c|c|c|c|c|c|c|c|c|c|}
\hline Espécie & $\mathrm{N}$ & $\mathrm{P}$ & $\begin{array}{l}\mathrm{AB} \\
\left(\mathrm{m}^{2}\right)\end{array}$ & $\begin{array}{l}\text { Amd } \\
(\mathrm{m})\end{array}$ & $\begin{array}{c}\operatorname{Amx} \\
(\mathrm{m})\end{array}$ & $\begin{array}{c}\text { DA } \\
\left(\mathrm{n}^{\circ} \mathrm{ha}^{-1}\right)\end{array}$ & $\begin{array}{c}\text { DoA } \\
\left(\mathrm{m}^{2} \mathrm{ha}^{-1}\right)\end{array}$ & $\begin{array}{l}\text { DR } \\
(\%)\end{array}$ & $\begin{array}{l}\text { DoR } \\
(\%)\end{array}$ & $\mathrm{VC}$ \\
\hline Siparuna guianensis & 19 & 11 & 0,095 & 5,9 & 10,0 & 9,1 & 0,046 & 0,61 & 0,17 & 0,78 \\
\hline Diatenopteryx sorbifolia & 6 & 6 & 0,333 & 13,5 & 30,0 & 2,9 & 0,160 & 0,19 & 0,59 & 0,78 \\
\hline Eugenia pyriformis & 17 & 15 & 0,130 & 7,8 & 16,0 & 8,2 & 0,062 & 0,54 & 0,23 & 0,77 \\
\hline Zanthoxylum caribaeum & 11 & 11 & 0,236 & 12,2 & 25,0 & 5,3 & 0,114 & 0,35 & 0,42 & 0,77 \\
\hline Guatteria nigrescens & 16 & 13 & 0,135 & 9,3 & 17,0 & 7,7 & 0,065 & 0,51 & 0,24 & 0,75 \\
\hline Casearia decandra & 15 & 11 & 0,151 & 11,4 & 18,0 & 7,2 & 0,073 & 0,48 & 0,27 & 0,75 \\
\hline Cordia sellowiana & 6 & 5 & 0,283 & 16,8 & 21,0 & 2,9 & 0,136 & 0,19 & 0,50 & 0,69 \\
\hline Cordia magnoliifolia & 10 & 9 & 0,197 & 7,0 & 12,0 & 4,8 & 0,095 & 0,32 & 0,35 & 0,67 \\
\hline Machaerium brasiliense & 12 & 7 & 0,166 & 10,8 & 22,0 & 5,8 & 0,080 & 0,38 & 0,29 & 0,67 \\
\hline Cassia ferruginea & 5 & 3 & 0,291 & 12,2 & 17,0 & 2,4 & 0,140 & 0,16 & 0,51 & 0,67 \\
\hline Styrax latifolius & 5 & 3 & 0,286 & 19,0 & 22,0 & 2,4 & 0,137 & 0,16 & 0,50 & 0,66 \\
\hline Casearia lasiophylla & 15 & 12 & 0,096 & 9,0 & 23,0 & 7,2 & 0,046 & 0,48 & 0,17 & 0,65 \\
\hline Tapirira guianensis & 7 & 5 & 0,246 & 11,4 & 20,0 & 3,4 & 0,118 & 0,22 & 0,43 & 0,65 \\
\hline Prunus brasiliensis & 11 & 8 & 0,166 & 8,2 & 20,0 & 5,3 & 0,080 & 0,35 & 0,29 & 0,64 \\
\hline Metrodorea stipularis & 6 & 4 & 0,248 & 16,0 & 22,0 & 2,9 & 0,119 & 0,19 & 0,44 & 0,63 \\
\hline Calyptranthes clusiifolia & 11 & 8 & 0,129 & 10,1 & 19,0 & 5,3 & 0,062 & 0,35 & 0,23 & 0,58 \\
\hline Ilex cerasifolia & 14 & 12 & 0,061 & 7,3 & 14,0 & 6,7 & 0,029 & 0,45 & 0,11 & 0,56 \\
\hline Campomanesia guazumifolia & 10 & 9 & 0,136 & 7,7 & 11,0 & 4,8 & 0,066 & 0,32 & 0,24 & 0,56 \\
\hline Qualea cordata & 5 & 5 & 0,219 & 10,6 & 22,0 & 2,4 & 0,105 & 0,16 & 0,39 & 0,55 \\
\hline Astronium graveolens & 5 & 4 & 0,219 & 14,1 & 23,0 & 2,4 & 0,105 & 0,16 & 0,39 & 0,55 \\
\hline Ocotea glaziovii & 3 & 3 & 0,256 & 15,7 & 21,0 & 1,4 & 0,123 & 0,10 & 0,45 & 0,55 \\
\hline Myrsine umbellata & 7 & 3 & 0,179 & 7,6 & 12,0 & 3,4 & 0,086 & 0,22 & 0,32 & 0,54 \\
\hline Cecropia glaziovii & 10 & 8 & 0,109 & 14,4 & 20,0 & 4,8 & 0,053 & 0,32 & 0,19 & 0,51 \\
\hline Chrysophyllum gonocarpum & 7 & 7 & 0,164 & 11,3 & 17,0 & 3,4 & 0,079 & 0,22 & 0,29 & 0,51 \\
\hline Ouratea semiserrata & 11 & 9 & 0,085 & 9,0 & 17,0 & 5,3 & 0,041 & 0,35 & 0,15 & 0,50 \\
\hline Eriotheca candolleana & 4 & 3 & 0,196 & 11,3 & 13,0 & 1,9 & 0,094 & 0,13 & 0,35 & 0,48 \\
\hline Amaioua guianensis & 10 & 8 & 0,072 & 8,2 & 13,5 & 4,8 & 0,034 & 0,32 & 0,13 & 0,45 \\
\hline Jacaranda macrantha & 9 & 7 & 0,091 & 6,4 & 11,0 & 4,3 & 0,044 & 0,29 & 0,16 & 0,45 \\
\hline Sloanea monosperma & 10 & 9 & 0,069 & 6,3 & 9,0 & 4,8 & 0,033 & 0,32 & 0,12 & 0,44 \\
\hline Senna macranthera & 11 & 8 & 0,050 & 7,8 & 10,5 & 5,3 & 0,024 & 0,35 & 0,09 & 0,44 \\
\hline Ocotea elegans & 7 & 7 & 0,122 & 6,4 & 10,0 & 3,4 & 0,059 & 0,22 & 0,22 & 0,44 \\
\hline Leucochloron incuriale & 9 & 5 & 0,087 & 8,6 & 15,0 & 4,3 & 0,042 & 0,29 & 0,15 & 0,44 \\
\hline Casearia arborea & 9 & 7 & 0,080 & 9,1 & 16,0 & 4,3 & 0,038 & 0,29 & 0,14 & 0,43 \\
\hline Seguieria langsdorffii & 8 & 6 & 0,095 & 7,4 & 12,0 & 3,8 & 0,046 & 0,26 & 0,17 & 0,43 \\
\hline Byrsonima laxiflora & 9 & 7 & 0,072 & 9,3 & 24,0 & 4,3 & 0,035 & 0,29 & 0,13 & 0,42 \\
\hline Ocotea velutina & 9 & 4 & 0,054 & 6,4 & 8,0 & 4,3 & 0,026 & 0,29 & 0,10 & 0,39 \\
\hline Luehea divaricata & 2 & 2 & 0,186 & 12,5 & 13,0 & 1,0 & 0,090 & 0,06 & 0,33 & 0,39 \\
\hline Lonchocarpus cultratus & 4 & 4 & 0,139 & 11,4 & 12,0 & 1,9 & 0,067 & 0,13 & 0,25 & 0,38 \\
\hline Miconia albicans & 10 & 3 & 0,027 & 4,4 & 5,0 & 4,8 & 0,013 & 0,32 & 0,05 & 0,37 \\
\hline Cordia ecalyculata & 3 & 3 & 0,144 & 8,8 & 11,5 & 1,4 & 0,069 & 0,10 & 0,25 & 0,35 \\
\hline Nectandra megapotamica & 2 & 2 & 0,165 & 22,0 & 25,0 & 1,0 & 0,079 & 0,06 & 0,29 & 0,35 \\
\hline Ocotea odorifera & 6 & 5 & 0,068 & 9,0 & 15,0 & 2,9 & 0,033 & 0,19 & 0,12 & 0,31 \\
\hline Zanthoxylum rhoifolium & 5 & 5 & 0,073 & 12,6 & 20,0 & 2,4 & 0,035 & 0,16 & 0,13 & 0,29 \\
\hline Salacia elliptica & 5 & 4 & 0,075 & 8,8 & 11,0 & 2,4 & 0,036 & 0,16 & 0,13 & 0,29 \\
\hline Aniba firmula & 3 & 3 & 0,105 & 16,3 & 27,0 & 1,4 & 0,051 & 0,10 & 0,19 & 0,29 \\
\hline Guapira graciliflora & 7 & 7 & 0,032 & 5,8 & 10,0 & 3,4 & 0,015 & 0,22 & 0,06 & 0,28 \\
\hline Nectandra lanceolata & 2 & 2 & 0,123 & 9,5 & 10,0 & 1,0 & 0,059 & 0,06 & 0,22 & 0,28 \\
\hline Psidium rufum & 3 & 3 & 0,097 & 13,3 & 17,0 & 1,4 & 0,047 & 0,10 & 0,17 & 0,27 \\
\hline Machaerium nictitans & 2 & 2 & 0,119 & 14,0 & 25,0 & 1,0 & 0,057 & 0,06 & 0,21 & 0,27 \\
\hline Maytenus ilicifolia & 6 & 5 & 0,040 & 5,6 & 7,0 & 2,9 & 0,019 & 0,19 & 0,07 & 0,26 \\
\hline
\end{tabular}


Tabela 4. (continuação).

\begin{tabular}{|c|c|c|c|c|c|c|c|c|c|c|}
\hline Espécie & $\mathrm{N}$ & $\mathrm{P}$ & $\begin{array}{l}\mathrm{AB} \\
\left(\mathrm{m}^{2}\right)\end{array}$ & $\begin{array}{l}\text { Amd } \\
(\mathrm{m})\end{array}$ & $\begin{array}{c}\text { Amx } \\
(\mathrm{m})\end{array}$ & $\begin{array}{c}\text { DA } \\
\left(\mathrm{n}^{\circ} \mathrm{ha}^{-1}\right)\end{array}$ & $\begin{array}{c}\text { DoA } \\
\left(\mathrm{m}^{2} \mathrm{ha}^{-1}\right)\end{array}$ & $\begin{array}{l}\text { DR } \\
(\%)\end{array}$ & $\begin{array}{l}\text { DoR } \\
(\%)\end{array}$ & $\mathrm{VC}$ \\
\hline Zanthoxylum monogynum & 6 & 3 & 0,037 & 6,0 & 7,0 & 2,9 & 0,018 & 0,19 & 0,07 & 0,26 \\
\hline Syagrus romanzoffiana & 2 & 2 & 0,112 & 6,3 & 8,0 & 1,0 & 0,054 & 0,06 & 0,20 & 0,26 \\
\hline Inga cylindrica & 5 & 5 & 0,053 & 9,6 & 18,0 & 2,4 & 0,025 & 0,16 & 0,09 & 0,25 \\
\hline Gomidesia affinis & 5 & 5 & 0,051 & 7,0 & 11,0 & 2,4 & 0,024 & 0,16 & 0,09 & 0,25 \\
\hline Acacia glomerosa & 3 & 3 & 0,082 & 13,2 & 18,0 & 1,4 & 0,039 & 0,10 & 0,14 & 0,24 \\
\hline Siphoneugena densiflora & 5 & 2 & 0,045 & 6,4 & 10,0 & 2,4 & 0,022 & 0,16 & 0,08 & 0,24 \\
\hline Xylosma prockia & 4 & 4 & 0,057 & 11,8 & 17,0 & 1,9 & 0,027 & 0,13 & 0,10 & 0,23 \\
\hline Dendropanax cuneatus & 4 & 4 & 0,055 & 5,4 & 9,5 & 1,9 & 0,026 & 0,13 & 0,10 & 0,23 \\
\hline Machaerium hirtum & 3 & 3 & 0,072 & 11,7 & 17,0 & 1,4 & 0,035 & 0,10 & 0,13 & 0,23 \\
\hline Nectandra grandiflora & 1 & 1 & 0,115 & 10,0 & 10,0 & 0,5 & 0,055 & 0,03 & 0,20 & 0,23 \\
\hline Alibertia concolor & 3 & 3 & 0,056 & 6,2 & 8,5 & 1,4 & 0,027 & 0,10 & 0,10 & 0,20 \\
\hline Anadenanthera colubrina & 3 & 2 & 0,058 & 10,3 & 15,0 & 1,4 & 0,028 & 0,10 & 0,10 & 0,20 \\
\hline Styrax ferrugineus & 3 & 3 & 0,053 & 10,3 & 11,0 & 1,4 & 0,026 & 0,10 & 0,09 & 0,19 \\
\hline Roupala longepetiolata & 4 & 4 & 0,030 & 9,1 & 10,5 & 1,9 & 0,015 & 0,13 & 0,05 & 0,18 \\
\hline Casearia gossypiosperma & 4 & 4 & 0,027 & 9,3 & 12,0 & 1,9 & 0,013 & 0,13 & 0,05 & 0,18 \\
\hline Trichilia lepidota & 4 & 4 & 0,026 & 10,9 & 19,5 & 1,9 & 0,013 & 0,13 & 0,05 & 0,18 \\
\hline Ficus mexiae & 2 & 2 & 0,069 & 9,5 & 12,0 & 1,0 & 0,033 & 0,06 & 0,12 & 0,18 \\
\hline Cedrela fissilis & 3 & 2 & 0,043 & 10,0 & 13,0 & 1,4 & 0,021 & 0,10 & 0,08 & 0,18 \\
\hline Tibouchina stenocarpa & 4 & 2 & 0,024 & 7,6 & 8,0 & 1,9 & 0,012 & 0,13 & 0,04 & 0,17 \\
\hline Citronella paniculata & 3 & 3 & 0,037 & 6,0 & 8,0 & 1,4 & 0,018 & 0,10 & 0,07 & 0,17 \\
\hline Psidium cattleyanum & 3 & 2 & 0,038 & 8,0 & 9,0 & 1,4 & 0,018 & 0,10 & 0,07 & 0,17 \\
\hline Inga marginata & 1 & 1 & 0,075 & 9,0 & 9,0 & 0,5 & 0,036 & 0,03 & 0,13 & 0,16 \\
\hline Guarea macrophylla & 3 & 3 & 0,028 & 8,5 & 15,0 & 1,4 & 0,014 & 0,10 & 0,05 & 0,15 \\
\hline Cinnamomum glaziovii & 1 & 1 & 0,066 & 11,0 & 11,0 & 0,5 & 0,032 & 0,03 & 0,12 & 0,15 \\
\hline Eugenia sp. & 3 & 2 & 0,020 & 9,2 & 12,0 & 1,4 & 0,010 & 0,10 & 0,04 & 0,14 \\
\hline Myrcia rostrata & 2 & 1 & 0,046 & 12,5 & 15,0 & 1,0 & 0,022 & 0,06 & 0,08 & 0,14 \\
\hline Piptocarpha macropoda & 2 & 2 & 0,039 & 15,0 & 22,0 & 1,0 & 0,019 & 0,06 & 0,07 & 0,13 \\
\hline Maytenus glazioviana & 2 & 2 & 0,037 & 14,5 & 16,0 & 1,0 & 0,018 & 0,06 & 0,07 & 0,13 \\
\hline Psychotria deflexa & 3 & 2 & 0,014 & 6,5 & 10,0 & 1,4 & 0,007 & 0,10 & 0,03 & 0,13 \\
\hline Allophylus semidentatus & 3 & 3 & 0,011 & 5,2 & 6,0 & 1,4 & 0,006 & 0,10 & 0,02 & 0,12 \\
\hline Tibouchina sellowiana & 1 & 1 & 0,048 & 20,0 & 20,0 & 0,5 & 0,023 & 0,03 & 0,08 & 0,11 \\
\hline Peltophorum dubium & 2 & 2 & 0,029 & 17,5 & 20,0 & 1,0 & 0,014 & 0,06 & 0,05 & 0,11 \\
\hline Schefflera longepetiolata & 1 & 1 & 0,048 & 19,0 & 19,0 & 0,5 & 0,023 & 0,03 & 0,08 & 0,11 \\
\hline Diospyros inconstans & 2 & 1 & 0,024 & 7,0 & 9,0 & 1,0 & 0,012 & 0,06 & 0,04 & 0,10 \\
\hline Pera glabrata & 2 & 2 & 0,019 & 11,0 & 12,0 & 1,0 & 0,009 & 0,06 & 0,03 & 0,09 \\
\hline Zanthoxylum riedelianum & 1 & 1 & 0,036 & 10,0 & 10,0 & 0,5 & 0,017 & 0,03 & 0,06 & 0,09 \\
\hline Maprounea guianensis & 2 & 2 & 0,013 & 5,0 & 6,0 & 1,0 & 0,006 & 0,06 & 0,02 & 0,08 \\
\hline Allophylus edulis & 2 & 2 & 0,010 & 4,8 & 5,0 & 1,0 & 0,005 & 0,06 & 0,02 & 0,08 \\
\hline Coutarea hexandra & 2 & 2 & 0,009 & 3,5 & 4,0 & 1,0 & 0,004 & 0,06 & 0,02 & 0,08 \\
\hline Myrsine lancifolia & 2 & 2 & 0,009 & 8,0 & 11,0 & 1,0 & 0,004 & 0,06 & 0,02 & 0,08 \\
\hline Ocotea diospyrifolia & 1 & 1 & 0,030 & 13,0 & 13,0 & 0,5 & 0,014 & 0,03 & 0,05 & 0,08 \\
\hline Eugenia cerasiflora & 2 & 1 & 0,011 & 6,3 & 10,0 & 1,0 & 0,005 & 0,06 & 0,02 & 0,08 \\
\hline Aspidosperma ramiflorum & 1 & 1 & 0,027 & 12,0 & 12,0 & 0,5 & 0,013 & 0,03 & 0,05 & 0,08 \\
\hline Sorocea bonplandii & 2 & 2 & 0,008 & 5,5 & 6,0 & 1,0 & 0,004 & 0,06 & 0,01 & 0,07 \\
\hline Xylosma ciliatifolium & 2 & 2 & 0,008 & 5,0 & 5,0 & 1,0 & 0,004 & 0,06 & 0,01 & 0,07 \\
\hline Lonchocarpus muehlbergianus & 2 & 2 & 0,007 & 5,0 & 7,0 & 1,0 & 0,003 & 0,06 & 0,01 & 0,07 \\
\hline Endlicheria paniculata & 1 & 1 & 0,024 & 10,0 & 10,0 & 0,5 & 0,012 & 0,03 & 0,04 & 0,07 \\
\hline Solanum pseudoquina & 1 & 1 & 0,023 & 10,0 & 10,0 & 0,5 & 0,011 & 0,03 & 0,04 & 0,07 \\
\hline Zanthoxylum fagara & 1 & 1 & 0,018 & 18,0 & 18,0 & 0,5 & 0,009 & 0,03 & 0,03 & 0,06 \\
\hline Nectandra warmingii & 1 & 1 & 0,018 & 12,0 & 12,0 & 0,5 & 0,009 & 0,03 & 0,03 & 0,06 \\
\hline
\end{tabular}


Tabela 4. (continuação).

\begin{tabular}{|c|c|c|c|c|c|c|c|c|c|c|}
\hline Espécie & $\mathrm{N}$ & $\mathrm{P}$ & $\begin{array}{l}\mathrm{AB} \\
\left(\mathrm{m}^{2}\right)\end{array}$ & $\begin{array}{l}\text { Amd } \\
(\mathrm{m})\end{array}$ & $\begin{array}{c}\operatorname{Amx} \\
(\mathrm{m})\end{array}$ & $\begin{array}{c}\text { DA } \\
\left(\mathrm{n}^{\circ} \mathrm{ha}^{-1}\right)\end{array}$ & $\begin{array}{c}\text { DoA } \\
\left(\mathrm{m}^{2} h \mathrm{a}^{-1}\right)\end{array}$ & $\begin{array}{l}\mathrm{DR} \\
(\%)\end{array}$ & $\begin{array}{c}\text { DoR } \\
(\%)\end{array}$ & $\mathrm{VC}$ \\
\hline Ormosia arborea & 1 & 1 & 0,015 & 9,0 & 9,0 & 0,5 & 0,007 & 0,03 & 0,03 & 0,06 \\
\hline Myrcia tomentosa & 1 & 1 & 0,014 & 6,0 & 6,0 & 0,5 & 0,007 & 0,03 & 0,02 & 0,05 \\
\hline Garcinia gardneriana & 1 & 1 & 0,011 & 5,0 & 5,0 & 0,5 & 0,005 & 0,03 & 0,02 & 0,05 \\
\hline Ocotea aciphylla & 1 & 1 & 0,011 & 18,0 & 18,0 & 0,5 & 0,005 & 0,03 & 0,02 & 0,05 \\
\hline Persea pyrifolia & 1 & 1 & 0,010 & 10,0 & 10,0 & 0,5 & 0,005 & 0,03 & 0,02 & 0,05 \\
\hline Aspidosperma spruceanum & 1 & 1 & 0,009 & 9,0 & 9,0 & 0,5 & 0,004 & 0,03 & 0,02 & 0,05 \\
\hline Chrysophyllum marginatum & 1 & 1 & 0,008 & 6,0 & 6,0 & 0,5 & 0,004 & 0,03 & 0,01 & 0,04 \\
\hline Protium widgrenii & 1 & 1 & 0,008 & 8,5 & 8,5 & 0,5 & 0,004 & 0,03 & 0,01 & 0,04 \\
\hline Euterpe edulis & 1 & 1 & 0,007 & 6,0 & 6,0 & 0,5 & 0,003 & 0,03 & 0,01 & 0,04 \\
\hline Styrax camporus & 1 & 1 & 0,007 & 6,5 & 6,5 & 0,5 & 0,003 & 0,03 & 0,01 & 0,04 \\
\hline Nectandra cissiflora & 1 & 1 & 0,006 & 20,0 & 20,0 & 0,5 & 0,003 & 0,03 & 0,01 & 0,04 \\
\hline Daphnopsis fasciculata & 1 & 1 & 0,005 & 7,0 & 7,0 & 0,5 & 0,003 & 0,03 & 0,01 & 0,04 \\
\hline Cybistax antisyphillitica & 1 & 1 & 0,005 & 12,0 & 12,0 & 0,5 & 0,003 & 0,03 & 0,01 & 0,04 \\
\hline Nectandra nitidula & 1 & 1 & 0,005 & 10,0 & 10,0 & 0,5 & 0,002 & 0,03 & 0,01 & 0,04 \\
\hline Peltogyne angustiflora & 1 & 1 & 0,005 & 3,5 & 3,5 & 0,5 & 0,002 & 0,03 & 0,01 & 0,04 \\
\hline Hymenaea courbaril & 1 & 1 & 0,004 & 6,5 & 6,5 & 0,5 & 0,002 & 0,03 & 0,01 & 0,04 \\
\hline Zanthoxylum petiolare & 1 & 1 & 0,004 & 6,0 & 6,0 & 0,5 & 0,002 & 0,03 & 0,01 & 0,04 \\
\hline Eugenia handroana & 1 & 1 & 0,004 & 5,0 & 5,0 & 0,5 & 0,002 & 0,03 & 0,01 & 0,04 \\
\hline Ficus insipida & 1 & 1 & 0,004 & 6,5 & 6,5 & 0,5 & 0,002 & 0,03 & 0,01 & 0,04 \\
\hline Solanum leucodendron & 1 & 1 & 0,004 & 4,0 & 4,0 & 0,5 & 0,002 & 0,03 & 0,01 & 0,04 \\
\hline Duguetia lanceolata & 1 & 1 & 0,004 & 7,0 & 7,0 & 0,5 & 0,002 & 0,03 & 0,01 & 0,04 \\
\hline Blepharocalyx salicifolius & 1 & 1 & 0,003 & 5,0 & 5,0 & 0,5 & 0,002 & 0,03 & 0,01 & 0,04 \\
\hline Rhamnidium elaeocarpum & 1 & 1 & 0,003 & 6,0 & 6,0 & 0,5 & 0,002 & 0,03 & 0,01 & 0,04 \\
\hline Balfourodendron riedelianum & 1 & 1 & 0,003 & 5,0 & 5,0 & 0,5 & 0,001 & 0,03 & 0,00 & 0,03 \\
\hline Xylopia brasiliensis & 1 & 1 & 0,002 & 7,0 & 7,0 & 0,5 & 0,001 & 0,03 & 0,00 & 0,03 \\
\hline Guarea kunthiana & 1 & 1 & 0,002 & 12,0 & 12,0 & 0,5 & 0,001 & 0,03 & 0,00 & 0,03 \\
\hline Helicteres ovata & 1 & 1 & 0,002 & 6,5 & 6,5 & 0,5 & 0,001 & 0,03 & 0,00 & 0,03 \\
\hline Erythroxylum deciduum & 1 & 1 & 0,002 & 6,0 & 6,0 & 0,5 & 0,001 & 0,03 & 0,00 & 0,03 \\
\hline Todas as 174 espécies & 3120 & 52 & 56,662 & 9,4 & 30,0 & 1500,0 & 27,24110 & 00,0 & 00,00 & 00,00 \\
\hline
\end{tabular}

lho et al. 1994a). Fato semelhante ocorre com a área basal: das 10 espécies com maior dominância absoluta; Croton floribundus, Piptadenia gonoacantha, Albizia polycephala, Miconia cinnamomifolia, Colubrina glandulosa, Platycyamus regnellii, Ocotea corymbosa, Machaerium stipitatum, Coccoloba warmingiie Actinostemon concolor, apenas $O$. corymbosa ocorreu entre as dez de maior dominância na Reserva da UFLA e só $C$. glandulosa foi exclusiva da Mata da Subestação.

A grande dessemelhança entre as comunidades arbóreas de duas florestas tão próximas fisicamente indicaria que os fragmentos de floresta semidecídua da região podem apresentar diferenças estruturais e florísticas marcantes.
Este fato é muito relevante do ponto de vista da conservação, ao provar que vários fragmentos pequenos espalhados na paisagem podem encerrar comunidades muito distintas, não devendo ser tratados como amostras semelhantes de uma totalidade antes homogênea. Esta é a realidade atual da região do Alto Rio Grande, onde a alta heterogeneidade ambiental deve ter sido correspondida por uma grande variação florística e estrutural das florestas, representada de forma imperfeita pelos atuais fragmentos, os quais, justamente por isto, merecem rigorosa conservação.

O número de espécies raras sensu Kageyama e Gandara (1993) foi 59 espécies com menos de uma árvore por hectare, ou seja, 34\% do total. Este valor sugere que muitas populações 
podem vir a sofrer sérias dificuldades de conservação a longo prazo. Entre essas espécies, estão o palmito, Euterpe edulis, o pau-marfim, Balfourodendron riedelianum, e o guarabu, Peltogyne angustiflora, todas extremamente raras na região. Outras espécies raras encontradas na Mata da Subestação incluem ainda o jequitibárosa, Cariniana legalis, e a casca-d'anta, Cinnamodendron dinizii.

Correlações entre espécies e variáveis ambientais - A análise de correspondência canônica (CCA) indicou fortes correlações entre a distribuição das abundâncias das espécies na amostra e as variáveis ambientais utilizadas. Os autovalores dos dois primeiros eixos de ordenação, de 0,131 e 0,118 , são baixos, indicando gradientes curtos, ou seja, a maioria das espécies ocorre em todo o gradiente, variando essencialmente suas abundâncias (ter Braak 1988, 1995). Estes dois eixos explicaram apenas 6,7 e 6,1\% da variância global dos dados (total acumulado: 12,9\%), indicando que muito 'ruído' permaneceu sem explicação. No entanto, baixos valores de variância percentual para abundâncias de espécies são comuns em dados de vegetação e não prejudicam a significância das relações espécie-ambiente (ter Braak 1988). De fato, a CCA produziu valores consideravelmente altos para as correlações espécie-ambiente nos dois primeiros eixos: $0,89 \mathrm{e}$ 0,87 . Além disso, o teste de permutação de Monte Carlo indicou que as abundâncias das espécies e as variáveis ambientais foram significativamente correlacionadas $(P<0.01$ para os dois primeiros eixos).

As variáveis ambientais mais fortemente correlacionadas com o primeiro eixo foram, em ordem decrescente, areia, $\mathrm{pH}$, argila e saturação por bases; com o segundo eixo, silte, saturação por bases, cota média, argila, $\mathrm{pH}$ e $\mathrm{Al}$ (Tab. 5). As correlações ponderadas mostraram também que todas as variáveis, menos a areia, foram fortemente correlacionadas com a cota média, confirmando a tendência de variação catenária para a maioria das propriedades dos solos. Os dois eixos de ordenação distinguiram, com grande clareza, os subgrupos de solo, concentrando as parcelas de Nitossolo no quadrante superior direito, as de Cambissolo no quadrante superior esquerdo, as de Latossolo B do centro para a parte inferior direita do diagrama, ficando as de Latossolo A numa posição central (Fig. 3). Esta separação se fez com base principalmente nos valores mais elevados de saturação por bases, $\mathrm{pH}$ e silte, nas parcelas de Nitossolo, bem como os valores mais elevados de $\mathrm{Al}$ nos demais solos. Maiores valores de areia e menores de argila discriminaram as parcelas de Cambissolo das de Latossolo B, respectivamente.

Os padrões indicados pela CCA são muito coerentes com o gradiente de fertilidade crescente e drenagem mais forte, representado pela sequiência Nitossolo $\rightarrow$ Cambissolo/Latossolo $\mathrm{A} \rightarrow$ Latossolo B e que já se fizera evidente com a análise das propriedades dos solos. A situação imprecisa dos Latossolo A no gradiente aparece como intermediária no diagrama da CCA (Fig. 3). Como os gradientes de estado nutricional e regime de água nos solos são muito coincidentes, fica difícil separar seus efeitos sobre a distribuição de espécies, ou mesmo colocar as variáveis em ordem de importância.

O fato mais notável emergindo das análises é que as variações das condições do substrato (minerais + água) mostraram-se preponderantes na determinação da distribuição das espécies no fragmento, sendo o fator borda descartado por falta de correlação significativa. O fator borda foi identificado como um dos mais fortemente correlacionados com a distribuição de espécies na Reserva da UFLA, mas o substrato nesta última era muito homogêneo (Oliveira-Filho et al. 1997), facilitando a detecção da influência da borda. Não se pode afirmar, portanto, que não haja efeito borda sobre a distribuição das espécies na Mata da Subestação, mas apenas que, se esta influência existir, ela é mascarada pela heterogeneidade do substrato. Estudos de efeito bor- 


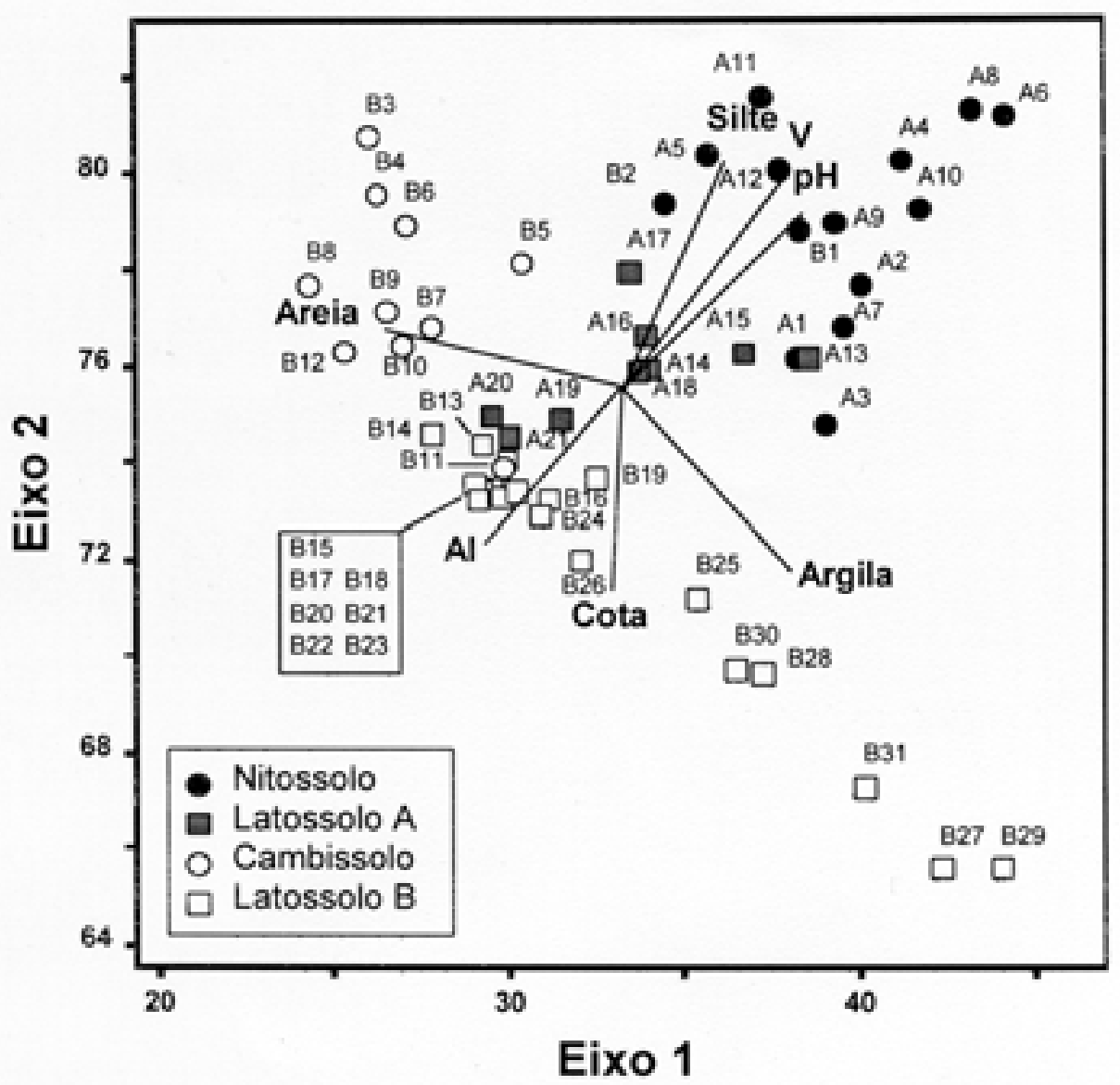

Figura 3. Diagrama de ordenação das parcelas e variáveis ambientais (setas) nos dois primeiros eixos de ordenação produzidos pela análise de correspondência canônica (CCA) dos dados de número de indivíduos das 64 espécies mais abundantes (> 10 indivíduos) em 51 parcelas amostradas na Mata da Subestação, Lavras, MG. As parcelas encontram-se classificadas nos subgrupos de solo (vide Figura 1).

da na composição e estrutura de comunidades arbóreas, como o de Laurence et al. (1998) devem, como premissa, se assegurar do controle das variáveis relacionadas ao substrato.

A ordenação das espécies pela CCA (Fig. 4) mostrou como mais fortemente relacionadas com as cotas mais elevadas, solos mais fortemente drenados, ácidos e pobres em nutrientes as espécies Miconia albicans, Senna macranthera, Miconia argyrophylla $\mathrm{e}$ Luehea grandiflora. No caso das três últimas espécies, a tendência de preferir solos mais secos já foi registrada por outros autores (Lorenzi 1992; Souza 2001). Para as espécies mais fortemente correlacionadas com as condições opostas (solos de cotas mais baixas, com drenagem moderada, menos ácidos e mais ricos em nutrientes); Prunus brasiliensis, Guazuma ulmifolia, Maclura tinctoria, Nectandra oppositifolia e Eugenia florida, também há confimações de outros estudos: $M$. tinctoria e $G$. ulmifolia são consideradas indicadoras de solos mesotróficos e E. florida de solos mais úmidos (Lorenzi 1992; 
Tabela 5. Variáveis ambientais utilizadas na análise de correspondência canônica (CCA) e suas correlações internas com os dois primeiros eixos de ordenação e matriz de correlações ponderadas entre as sete variáveis. Correlações $>0.5$, são indicados em negrito.

\begin{tabular}{|c|c|c|c|c|c|c|c|c|}
\hline \multirow{2}{*}{$\begin{array}{l}\text { Variáveis } \\
\text { ambientais }\end{array}$} & \multicolumn{2}{|c|}{ Correlações } & \multicolumn{6}{|c|}{ Variáveis ambientais } \\
\hline & Eixo 1 & Eixo 2 & Cota $\mathrm{m}$. & $\mathrm{pH}$ & $\mathrm{Al}$ & Sat.bases & Areia & Argila \\
\hline Cota média & -0.04 & -0.78 & - & & & & & \\
\hline $\mathrm{pH}$ & 0.66 & 0.66 & -0.55 & - & & & & \\
\hline $\mathrm{Al}$ & -0.51 & -0.61 & 0.64 & -0.76 & - & & & \\
\hline Saturação por bases & 0.56 & 0.80 & -0.69 & 0.93 & -0.80 & - & & \\
\hline Areia & -0.87 & 0.22 & -0.36 & -0.35 & 0.19 & -0.25 & - & \\
\hline Argila & 0.61 & -0.71 & 0.73 & -0.11 & 0.22 & -0.25 & -0.83 & - \\
\hline Silte & 0.38 & 0.87 & 0.68 & 0.78 & -0.71 & 0.85 & -0.22 & -0.37 \\
\hline
\end{tabular}

Oliveira-Filho \& Ratter 1995). Entre as espécies associadas aos solos intermediários em fertilidade e umidade (Cambissolos), G. jasminiflora é formadora de sub-bosques de florestas sobre solos de fertilidade média a alta (Oliveira-Filho et al. 1994b), enquanto M. cinnamomifolia e Vismia brasiliensis são pioneiras ou secundárias iniciais em solos com boa drenagem (Lorenzi 1992).

Os fragmentos florestais são retalhos de uma floresta que foi contínua em um passado não muito distante. Essa floresta pode ter incluído uma considerável variação de condições ambientais e, conseqüentemente, de estrutura da comunidade arbórea. Em florestas contínuas, as mudanças são geralmente graduais, na forma de ecótonos ou contínuos, mas, em fragmentos, as bordas abruptas podem levar à ilusão de que estes são homogêneos. Por pequeno que seja, um fragmento pode conter várias peças de mosaico de vegetação relacionadas a diferenças de substrato, à fase sucessional e ou ao efeito borda. Essa complexa realidade deve ser levada em consideração quando se procuram meios de conservar essa valiosa e ameaçada riqueza que é a diversidade biológica dos remanescentes de floresta tropical.

\section{Referências bibliográficas}

Angiosperm Phylogeny Group 1998. An ordinal classification for the families of flowering plants. Annals of the Missouri Botanical Garden 85(4): 531-553.
Ashton, P. S. 1990. Species richness in tropical forests. Pp. 239-251. In: L. B. Holm-Nielsen, I. C. Nielsen \& H. Balslev (Eds.). Tropical Forests - Botanical Dynamics, Speciation and Diversity. Academic Press, London.

Botrel, R. T. 2001. Fragmentação florestal no município de Ingaí, MG: composição florística, estrutura da comunidade arbórea e etnobotânica. Dissertação de Mestrado, Universidade Federal de Lavras, Lavras.

Brower, J. E. \& Zar, J. H. 1984. Field and Laboratory Methods for General Ecology. Wm. C. Brown Pub, Dubuque.

Buckman, H. O. \& Brady, N. C. 1969. The nature and properties of soils. Macmillan, London.

Curi, N.; Larach, J. O. I; Kämpf, N.; Moniz, A. C. \& Fontes, L. E. F. 1993. Vocabulário de ciência do solo. Sociedade Brasileira de Ciência do Solo, Campinas.

EMBRAPA 1997. Manual de métodos de análise de solo. Empresa Brasileira de Pesquisa Agropecuária, Centro Nacional de Pesquisa de Solos, Rio de Janeiro.

EMBRAPA 1999. Sistema brasileiro de classificação de solos. Empresa Brasileira de Pesquisa Agropecuária, Centro Nacional de Pesquisa de Solos, Rio de Janeiro.

FAO. 1993. Forest Resource Assessment 1990. Tropical countries. FAO Foresty Paper 112. Food and Agriculture Organization, Roma.

Kageyama, P. \& Gandara, F. B. 1993. Dinâmica de populações de espécies arbóreas: implicações para o manejo e a conservação. Pp. 1-12. In: Anais do $3^{\circ}$ Simpósio de Ecossistemas da Costa Brasileira, Serra Negra 1993, EDUSP, v. 2, São Paulo.

Kapos, V. 1989. Effects of isolation on the water status of forest patches in the Brazilian Amazon. Journal 


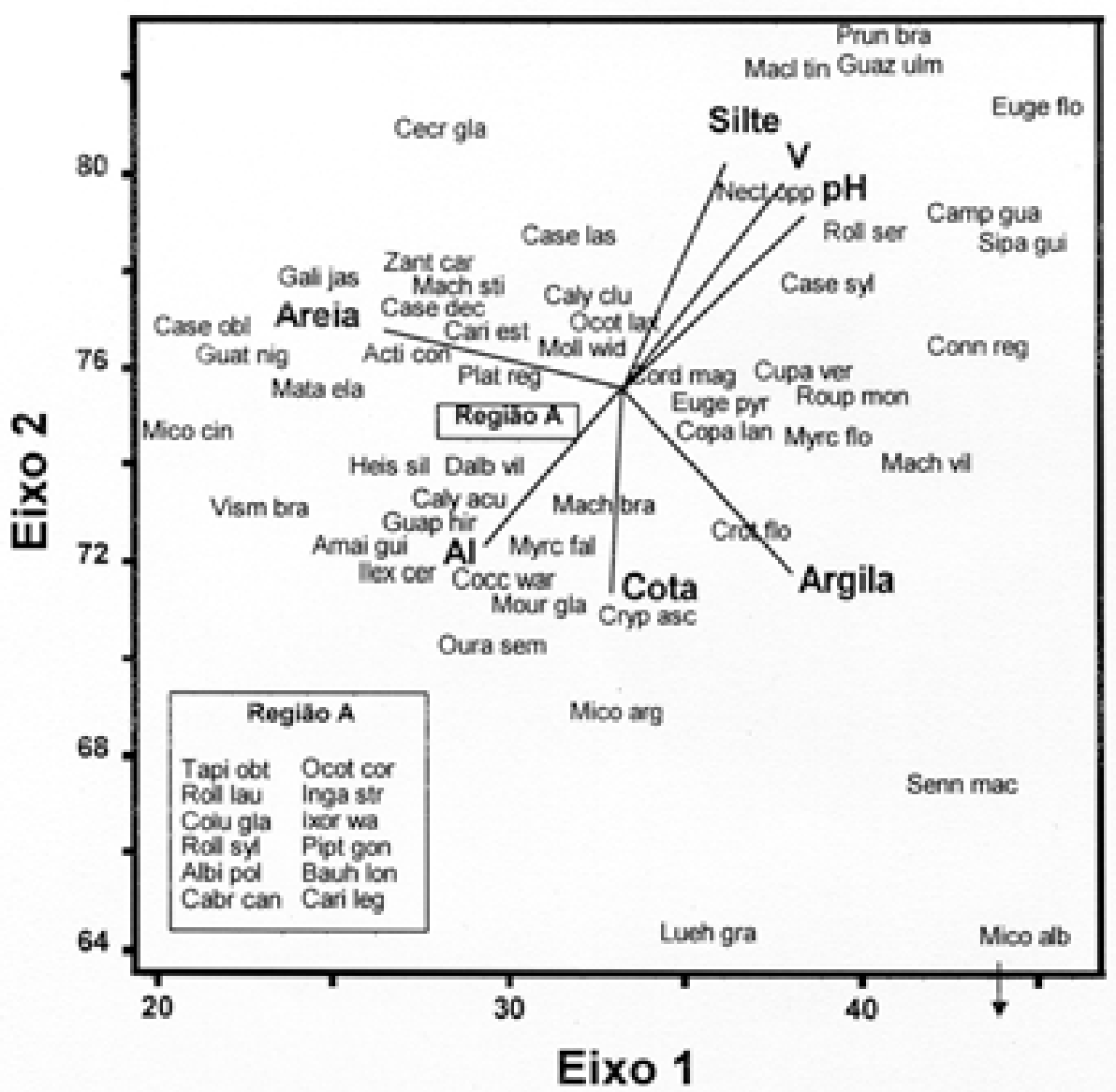

Figura 4. Diagrama de ordenação das espécies e variáveis ambientais (setas) nos dois primeiros eixos de ordenação produzidos pela análise de correspondência canônica (CCA) dos dados de número de indivíduos das 64 espécies mais abundantes ( $>10$ indivíduos) em 51 parcelas amostradas na Mata da Subestação, Lavras, MG. As espécies são identificadas por seus respectivos nomes científicos de forma abreviada (vide Tabela 3).

of Tropical Ecology 5(2): 173-185.

Laurence, W. F. \& Yensen, E. 1991. Predicting the impacts of edges in fragmented habitats. Biological Conservation 55(1): 77-92.

Laurence, W. F., Ferreira, L. V., Rankin-de-Merona, J. M. \& Laurence, S. G. 1998. Rain forest fragmentation and the dynamics of Amazonian tree communities. Ecology 79(6): 2032-2040.

Lorenzi, H. 1992. Árvores brasileiras; Manual de identificação e cultivo de plantas arbóreas nativas do Brasil. Ed. Plantarum, Nova Odessa.

Lovejoy, T. E. \& Bierregaard, R. O. 1990. Central Amazonian forests and the Minimum Critical Size of Ecosystems Project. Pp. 60-71. In: A. H. Gentry (Ed.). Four neotropical rainforests. Yale University
Press, New Haven.

Malcolm, J. R. 1994. Edge effects in central Amazonian forest fragments. Ecology 75(6): 2438-2445.

McCune, B. \& Mefford, M. J. 1999. Multivariate analysis of ecological data. MjM Software, Gleneden Beach.

Murcia, C. 1995. Edge effects in fragmented forests: implications for conservation. Trends in Ecology and Evolution 10(1): 58-62

Oliveira-Filho, A. T. 1994. Estudos ecológicos da vegetação como subsídio para programas de revegetação com espécies nativas: uma proposta metodológica. Cerne 1(1): $64-72$.

Oliveira-Filho, A. T. \& Fontes, M. A. L. 2000. Patterns of floristic differentiation among Atlantic forests in 
southeastern Brazil, and the influence of climate. Biotropica 32(4b): 793-810.

Oliveira-Filho, A. T. \& Ratter, J. A. 1995. A study of the origin of Central Brazilian Forests by the analysis of plant species distribution pattern. Edinburgh Journal of Botany 52(2): 141-194.

Oliveira-Filho, A. T.; Scolforo, J. R. S. \& Mello, J. M. 1994a. Composição florística e estrutura de um remanescente de floresta semidecidual montana em Lavras, MG. Revista Brasileira de Botânica 17(2): 167-182.

Oliveira-Filho, A. T.; Vilela, E. A.; Carvalho, D. A. \& Gavilanes, M. L. 1994b. Effects of soils and topography on the distribution of tree species in a tropical riverine forest in southeastern Brazil. Journal of Tropical Ecology 10(4): 483-508.

Oliveira-Filho, A. T.; Vilela, E. A.; Gavilanes, M. L. \& Carvalho, D. A. 1994c. Comparison of the woody flora and soils of six areas of montane semideciduous forest in southern Minas Gerais, Brazil. Edinburgh Journal of Botany 51(3): 355-389.

Oliveira-Filho, A. T.; Vilela, E. A.; Carvalho, D. A. \& Gavilanes, M. L. 1995. Estudos florísticos e fitossociológicos em remanescentes de matas ciliares do Alto e Médio Rio Grande. Boletim técnico 11.106-MA/PA-013, Companhia Energética de Minas Gerais (CEMIG), Belo Horizonte.

Oliveira-Filho, A. T.; Mello, J. M \& Scolforo, J. R. S. 1997. Effects of past disturbance and edges on tree community structure and dynamics within a fragment of tropical semideciduos forest in southeastern Brazil over a five year period (19871992). Plant Ecology 131(1): 45-66.

Oliveira-Filho, A. T.; Curi, N.; Vilela, E. A. \& Carva1ho, D. A. 2001. Variation in tree community composition and structure with changes in soil properties within a fragment of semideciduous forest in southeastern Brazil. Edinburgh Journal of Botany 58(1): 139-158.

Resende, M.; Curi, N. \& Santana, D. P. 1988. Pedologia e fertilidade do solo: interações e aplicações. Ministério da Agricultura, Brasília.

Resende, M.; Curi, N.; Rezende, S. B. \& Corrêa, G. F. 1995. Pedologia: base para a distinção de ambientes. Universidade Federal de Viçosa, Viçosa.

Rodrigues, L. A. 2001. Estudo florístico e estrutural da comunidade arbustiva e arbórea de uma floresta em Luminárias, MG, e informações etnobotânicas da população local. Dissertação de Mestrado, Universidade Federal de Lavras, Lavras.

Shepherd, G. J. 1994. Fitopac 2, Manual do usuário. UNICAMP, Campinas.
SOS Mata Atlântica 1998. Atlas da evolução dos remanescentes florestais e ecossistemas associados no domínio da Mata Atlântica no período 19901995. Fundação SOS Mata Atlântica, São Paulo.

Souza, J. S. 2001. Análise das variações florísticas e estruturais da comunidade arbórea de um fragmento de floresta semidecídua às margens do rio Capivari, Lavras, MG. Dissertação de Mestrado, Universidade Federal de Lavras, Lavras.

ter Braak, C. J. F. 1987. The analysis of vegetationenvironment relationships by canonical correspondence analysis. Vegetatio 69(1): 69-77.

ter Braak, C. J. F. 1988. CANOCO - A FORTRAN program for canonical community ordination by (Partial) (Detrended) (Canonical) correspondence analysis and redundancy analysis, version $\mathbf{2 . 1}$ Technical report LWA-88-2, TNO, Institute of Applied Computer Science, Wageningen .

ter Braak, C. J. F. 1995. Ordination. Pp. 91-173. In: R. H. G. Jongman, C. J. F. ter Braak \& O. F. R. van Tongeren (Eds.). Data analysis in community and landscape ecology. Cambridge University Press, Cambridge.

Van den Berg, E. \& Oliveira-Filho, A. T. 2000. Composição florística e estrutura fitossociológica de uma floresta ripária em Itutinga, MG, e comparação com outras áreas. Revista Brasileira de Botânica 22 (3): 231-253.

Viana, V. M. 1990. Biologia e manejo de fragmentos naturais. Pp. 113-118. In: Anais do $6^{\circ}$ Congresso Florestal Brasileiro. Campos do Jordão, 1990. EDUSP, São Paulo.

Viana, V. M. 1992. Restauração e manejo de fragmentos florestais. Pp. 400-406. In: Anais do $2^{\circ}$ Congresso Nacional sobre Essências Nativas. Campos do Jordão, 1992. Instituto Florestal/Secretaria do Meio Ambiente, São Paulo.

Viana, V. M. \& Tabanez, A. A. J. 1996. Biology and conservation of forest fragments in the Brazilian Atlantic moist forest. Pp. 151-167. In: J. Schelhas \& R. Greenberg (Eds.). Forest patches in tropical landscapes. Island Press, Washington.

Vilela, E. A. \& Ramalho, M. A. P. 1979. Análise das temperaturas e precipitações pluviométricas de Lavras, Minas Gerais. Ciência e Prática 3(1): 71-79.

Whitmore, T. C. 1997. Tropical forest disturbance, disappearance, and species loss. Pp. 3-14. In: W. F. Laurence \& R. O. Bierregaard (Eds.). Tropical Forest Remnants: Ecology, Management, and Conservation of Fragmented Communities. The University of Chicago Press, Chicago.

Zar, J. H. 1996. Biostatistical analysis. Prentice-Hall, New Jersey. 